\title{
Data-driven integration of hippocampal CA1 synapse physiology in silico
}

\author{
András Ecker ${ }^{*}$, Armando Romani ${ }^{1}$, Sára Sáray ${ }^{2,3}$, Szabolcs Káli ${ }^{2,3}$, Michele Migliore ${ }^{4}$, \\ Audrey Mercer ${ }^{5}$, Henry Markram ${ }^{1}$, Eilif Muller ${ }^{1}$, and Srikanth Ramaswamy ${ }^{{ }^{*}}$ \\ ${ }^{1}$ Blue Brain Project, École polytechnique fédérale de Lausanne, Campus Biotech, Geneva, Switzerland \\ ${ }^{2}$ Institute of Experimental Medicine, Hungarian Academy of Sciences, Budapest, Hungary \\ ${ }^{3}$ Pázmány Péter Catholic University, Faculty of Information Technology and Bionics, Budapest, \\ Hungary \\ ${ }^{4}$ Institute of Biophysics, National Research Council, Palermo, Italy \\ ${ }^{5}$ UCL School of Pharmacy, University College London, London, United Kingdom \\ ${ }^{*}$ Correspondence: andras.ecker@epfl.ch, srikanth.ramaswamy@epfl.ch
}

\begin{abstract}
1 Abstract
The anatomy and physiology of synaptic connections in rodent hippocampal CA1 have been exhaustively characterized in recent decades. Yet, the resulting knowledge remains disparate and difficult to reconcile. Here, we present a data-driven approach to integrate the current state-of-the-art knowledge on the synaptic anatomy and physiology of rodent hippocampal CA1, including axo-dendritic innervation patterns, number of synapses per connection, quantal conductances, neurotransmitter release probability, and short-term plasticity into a single coherent resource. First, we undertook an extensive literature review of paired-recordings of hippocampal neurons and compiled experimental data on their synaptic anatomy and physiology. The data collected in this manner is sparse and inhomogeneous due to the diversity of experimental techniques used by different labs, which necessitates the need for an integrative framework to unify these data. To this end, we extended a previously developed workflow for the neocortex to constrain a unifying in silico reconstruction of the synaptic physiology of CA1 connections. Our work identifies gaps in the existing knowledge and provides a complementary resource towards a more complete quantification of synaptic anatomy and physiology in the rodent hippocampal CA1 region.
\end{abstract}

Keywords: hippocampus, data integration, in silico modeling, CA1, synapse

\section{Introduction}

The hippocampal CA1 region is probably the most studied region of the mammalian brain and is thought to play a pivotal role in learning and memory (Bliss and Collingridge, 2013; Buzsáki, 1989). Neuronal microcircuits in the hippocampal CA1 region process and store information through a myriad of cell-type-specific synaptic connections. Previous studies have identified that hippocampal cell-types are connected through multiple synapses, which are positioned across distinct axo-dendritic domains with a diversity of short- and long-term dynamics, as well as synaptic strengths. Despite the wealth of data, we lack an integrative framework to reconcile the diversity of synaptic physiology, and therefore, identify knowledge gaps. There have been several 
recent attempts to integrate knowledge about the hippocampal CA1 (Bezaire and Soltesz, 2013; Wheeler et al., 2015), however, they were not focused on the dynamics of synaptic transmission. Recent attempts have extended the utility of the online resource hippocampome.org towards synaptic electrophysiology as well (Moradi and Ascoli, 2019). However, in the continuing spirit of hippocampome.org, the study is primarily a text mining-based collection of papers and parameters, which does not integrate these data into a unifying framework. As a way forward, we extended a previously developed workflow to integrate disparate data on the physiology of synaptic transmission in hippocampal CA1, identified and extrapolated organizing principles to predict knowledge gaps (Markram et al., 2015). We accounted for the dynamic and probabilistic nature of synaptic transmission by fitting experimental traces using a stochastic generalization of the Tsodyks-Markram short-term plasticity model (Tsodyks and Markram, 1997; Markram et al., 1998; Fuhrmann et al., 2002). After validating the number and location of synapses, parameterizing the release probability and reversal potentials, as well as depression, facilitation, and synaptic conductance rise and decay time constant for various hippocampal connection types, we corrected for space clamp artefacts in silico by tuning synaptic conductance to match the in vitro PSP (postsynaptic potential) amplitudes. We also considered temperature and extracellular calcium concentration $\left(\left[\mathrm{Ca}^{2+}\right]_{o}\right)$ differences, which were adjusted using Q10 and Hill scaling factors, respectively. The resulting models for a subset of hippocampal connection types were applied predictively to the remaining uncharacterized connection types by clustering them into nine groups based on synapse types and neuronal biomarkers and applying the known parameters within each group. Curated and predicted parameters presented here should serve as a resource to researchers aiming to model hippocampal synapses at any level, while the detailed methodology intends to give a guideline to utilize such a framework to integrate data from other brain regions or species.

\section{Methods}

\subsection{Circuit building and synapse anatomy}

A detailed model of the rat hippocampal CA1 area was built using the pipeline of Markram et al. (2015). Circuit building and rigorous validation will be detailed in a following article. In brief, single cell models with detailed morphologies including axonal reconstructions from Migliore et al. (2018) were populated in an atlas-based volume corresponding to the dimensions of the hippocampal CA1 region. Structural appositions between axons and dendrites were detected based on touch distance criteria and were later pruned to match experimentally reported bouton density, number of synapses per connections and connection probability using an algorithm to yield the functional connectome (Reimann et al., 2015). In this manner, the number and location of synapses for each connection were constrained in a data-driven manner. Connected cell-types were sampled from this circuit based on their inter-somatic distance.

\subsection{Dendritic features of single cell models}

Detailed biophysical models of pyramidal cells (PCs) and interneurons of the CA1 region from Migliore et al. (2018) were re-optimized and used in the present study. All models were constrained with active dendritic conductances but were optimized using only somatic features (Migliore et al., 2018). While the somatic responses to various step-current injections were correct, the dendrites of the single cell models turned out to be too excitable (single synaptic input leading to spikelets and somatic spikes). For this reason, single cell models were re-optimized with slightly reduced range for dendritic sodium channel density. PSP propagation and attenuation along the dendritic branches is a key feature for our synaptic conductance calibration, 
thus it was validated against experimental data using the HippoUnit framework (unpublished). To this end, excitatory postsynaptic current (EPSC) like currents were injected into the apical trunk of PCs with varying distance from the soma and PSPs were simultaneously measured at the local site of the injection and in the soma.

\subsection{Correcting for calcium ion concentration, temperature and liquid junc- tion potential}

Published parameters from different sources were corrected for differences arising from distinct experimental protocols. This included corrections for extracellular calcium levels different from 2 $\mathrm{mM}$, temperatures different from $34{ }^{\circ}$ Cand liquid junction potential (LJP) in the case of wholecell recordings using patch pipettes. The correction for $\left[\mathrm{Ca}^{2+}\right]_{o}$ was done by scaling the $U_{S E}$ parameter of the synapses (see below), using the Hill isotherm with $n=4$ (Hill, 1910):

$$
U_{S E}=U_{S E_{\max }} \frac{\left[C a^{2+}\right]_{o}^{4}}{K_{1 / 2}^{4}+\left[C a^{2+}\right]_{o}^{4}}
$$

where $U_{S E}$ is the absolute release probability and $U_{S E_{\max }}$ and $K_{1 / 2}$ are free parameters. $K_{1 / 2}$ values were taken from Rozov et al. (2001), $2.79(\mathrm{mM})$ for steep and $1.09(\mathrm{mM})$ for shallow calcium dependence and were shown to generalize well for other characterized pathways of the neocortex (see Supplementary Figure S11 in Markram et al. (2015)). In the absence of hippocampus specific data, we followed the approach of Markram et al. (2015) and assumed a steep dependence in $\mathrm{PC}$ to $\mathrm{PC}$ and $\mathrm{PC}$ to distal dendrite targeting inhibitory (O-LM) cells, and a shallow dependence between $\mathrm{PC}$ to proximal targeting cells $(\mathrm{PV}+\mathrm{BC}$ (basket cell), $\mathrm{CCK}+\mathrm{BC}$, AAC). For experimentally uncharacterized pathways an intermediate calcium dependence was used, as the average of the steep and shallow ones. Temperature correction of kinetic parameters such as rise and decay time constants were realized by multiplying them with Q10 scaling factors:

$$
\tau_{\text {sim }}=\tau_{\text {exp }} \times Q 10^{\left(T_{\text {sim }}-T_{\text {exp }}\right) / 10}
$$

where $\tau$ is the time constant, Q10 is an empirically determined, receptor-specific parameter, $T_{\text {sim }}=34^{\circ} \mathrm{C}$ is the temperature used in the simulations, while $T_{\text {exp }}$ is the temperature of the experiment. Holding potentials were corrected by the theoretical LJP (Neher, 1992). These potentials arise from the differences in solutions in the pipette and bath and are in $2-12 \mathrm{mV}$ range for the standard solutions. Theoretical LJPs were calculated from the reported pipette and bath solutions with the Clampex 11 software.

\subsection{Short-term plasticity model fitting}

Short-term plasticity (STP) of synapse dynamics was fit by the Tsodyks-Markram (TM) model (Tsodyks and Markram, 1997). The model assumes that all synaptic connections have a finite amount of resources. Each presynaptic action potential utilizes a certain fraction of available resource $(R)$ with a release probability $(U)$, which then recovers. Over the years, the model has been refined and enriched to capture for example short-term facilitation and multi-vesicular release (MVR) (Markram et al., 1998; Loebel et al., 2009). The differential equations are as follows (see Supplementary Methods for comparison of different versions of the TM model):

$$
\frac{d R(t)}{d t}=\frac{1-R(t)}{D}-U(t) R(t) \delta\left(t-t_{\text {spike }}\right)
$$

$$
\frac{d U(t)}{d t}=\frac{U_{S E}-U(t)}{F}-U_{S E}(1-U(t)) \delta\left(t-t_{\text {spike }}\right)
$$


where $D$, and $F$ and are depression and facilitation recovery time constants respectively, $U_{S E}$ is the absolute release probability also known as the release probability in the absence of facilitation. $\delta(t)$ is the Dirac delta function and $t_{\text {spike }}$ indicates the timing of a presynaptic spike. Each action potential in a train elicits an $A_{S E} U\left(t_{\text {spike }}\right) R\left(t_{\text {spike }}\right)$ amplitude PSC, where $A_{S E}$ is the absolute synaptic efficacy. $R=1$ and $U=U_{S E}$ are assumed before the first spike. $U_{S E}, D, F$ and $A_{S E}$ free parameters of the model were fit to experimentally recorded PSCs in Kohus et al. (2016) using a multiobjective genetic algorithm with BluePyOpt (Van Geit et al., 2016). Different frequency stimulations $(10,20$ and $40 \mathrm{~Hz})$ were fit together for better generalization. To correctly compare the coefficient of variation (CV, std/mean) of first PSC amplitudes, measurement noise was added to the simulated traces (Barros-Zulaica et al., 2019). To this end, noise parameters of in vitro traces were fitted and averaged for every different connection types and then stochastic noise generated with these extracted parameters was added to the corresponding in silico traces. Noise was described as an Ornstein-Uhlenbeck (OU) process. The OU process is a stationary Gauss-Markov process, which describes the velocity of the movement of a Brownian particle and is used in physics to describe noise relaxation (Bibbona et al., 2008). Mathematically it can be described with the following iterative equation:

$$
X(i)=X(i-1)-\frac{X(i-1)}{\tau} d t+\sigma \sqrt{\frac{2 d t}{\tau}} \mathcal{N}(0,1)
$$

where $d t$ is the time step of the signal, $\tau$ is the time constant fit to the exponential decay of the signal's autocorrelation function, $\sigma$ is the standard deviation of the signal and $\mathcal{N}(0,1)$ is a draw from the normal distribution.

\subsection{In silico synapse model}

The synapse model used in the simulations is based on the classical quantal model (Del Castillo and Katz, 1954), in which a synaptic connection is assumed to be composed of $N$ independent release sites, each of which has a probability of release, $p$ (function of $U_{S E}, D, F$ ), and contributes a quanta $q$ (function of the conductance $g(t)$ ) to the postsynaptic response (Ramaswamy et al., 2012, 2015; Markram et al., 2015; Chindemi, 2018). Conductances were modeled with double exponential kinetics:

$$
\begin{gathered}
g(t)=\hat{g}(d(t)-r(t)) \\
\frac{d d(t)}{d t}=-\frac{d(t)}{\tau_{d}}+A \frac{N_{r}}{N_{R R P}} \delta\left(t-t_{\text {spike }}\right) \\
\frac{d r(t)}{d t}=-\frac{r(t)}{\tau_{d}}+A \frac{N_{r}}{N_{R R P}} \delta\left(t-t_{\text {spike }}\right) \\
A=-e^{-t_{p} / \tau_{r}}+e^{-t_{p} / \tau_{d}}
\end{gathered}
$$

where $\hat{g}(\mathrm{nS})$ is the peak conductance, $d$ is the decaying component with time constant $\tau_{d}(\mathrm{~ms})$ and $r$ is the rising component with time constant $\tau_{r}(\mathrm{~ms})$. Rise time constants are set to $0.2 \mathrm{~ms}$ for all pathways following Markram et al. (2015). Synapses were normalized (with A normalization constant) such as they reach peak conductance at time to peak $t_{p}(\mathrm{~ms}) . N_{r}$ is the number of released vesicles. Vesicle release dynamics was governed by a hybrid stochastic STP model (Fuhrmann et al., 2002). The model releases a single vesicle with probability $U(t)$ (see TM model above) which then recovers. Vesicle recovery is an explicit process, meaning that compared to the canonical TM model, only fully recovered vesicles can be released. To this end, synaptic vesicles were implemented as 2-state (effective and recovering) Markov processes, in which staying in the 
Ecker et al.

recovered state at time $t$ was described as a survival process, with time constant $D$ (Chindemi, 2018):

$$
P_{\text {surv }}(t)=e^{-\left(t-t_{\text {spike }}\right) / D}
$$

The above-described model converges to the canonical TM model in the limit (number of trials $\longrightarrow \infty)$. MVR was implemented as $N$ independent vesicles being released with the same probability $U(t) . N_{R R P}$ is the size of the readily releasable pool of vesicles and normalizing with it can be seen as scaling down the quantal size $q$ of the quantal model in case of MVR, to keep the same mean PSP amplitudes, while changing only the variance (Barros-Zulaica et al., 2019). $N_{R R P}$ was tuned to match the CVs of first PSC amplitudes from Kohus et al. (2016). Due to the lack of available raw data with STP protocol (and electron microscopy confirmation of the number of functional release sites) for most connections, the assumption of MVR (Conti and Lisman, 2003; Christie and Jahr, 2006) with $N_{R R P}=2$ vesicles at each excitatory to excitatory terminal was used in this study, while all remaining non-tuned pathways were assumed to release single vesicles. See eg. Biro et al. (2005) and Gulyás et al. (1993) suggesting uni-vesicular release (UVR) for certain PC to interneuron connections. AMPAr and GABAr synaptic currents are then computed as:

$$
I(t)=g(t)\left(V_{m}(t)-E_{\text {rev }}\right)
$$

where $V_{m}(\mathrm{mV})$ is the membrane potential and $E_{\text {rev }}(\mathrm{mV})$ is the reversal potential of the given synapse. NMDAr currents depend also on $M g^{2+}$ block:

$$
I_{N M D A}(t)=g(t) m g(V)\left(V_{m}(t)-E_{r e v}\right)
$$

where $m g(V)$ is the LJP corrected Jahr-Stevens nonlinearity (Jahr and Stevens, 1990):

$$
m g(V)=\frac{1}{1+e^{-c_{1} V_{m}} C / c_{2}}
$$

where $C$ is the extracellular magnesium concentration and $c_{1}=0.062(1 / \mathrm{mV})$ and $c_{2}=2.62$ $(\mathrm{mM})$ are constants. NMDAr rise and decay time constants are Q10 corrected (Hestrin et al., 1990; Korinek et al., 2010) values from Andrasfalvy and Magee (2001): $\tau_{r}=3.9 \mathrm{~ms}, \tau_{d}=148.5$ ms. Peak NMDAr conductance $\hat{g}_{N M D A}(\mathrm{nS})$ is calculated from the AMPAr one by multiplying it with NMDA/AMPA peak conductance ratio. NMDA/AMPA peak conductance ratio $=1.22$ was taken from Groc et al. (2002); Myme et al. (2003). Synaptic currents are individually delayed based on axonal path length and conduction velocity of $300 \mu \mathrm{m} / \mathrm{ms}$ (Stuart et al., 1997) and an additional $0.1 \mathrm{~ms}$ delay of neurotransmitter release (Ramaswamy et al., 2012).

\subsection{Peak conductance tuning via in silico paired recordings}

Paired recordings were replicated in silico as follows: Firstly, pairs were selected from the circuit based on distance criteria used by experimentalist $(100 \mu \mathrm{m}$ cube for cells in the same layer and 200 $\mu \mathrm{m}$ cube for cell pairs from different layers). Secondly, postsynaptic cells were current-clamped to match the LJP-corrected holding potential specified in the experiments. It is important to note, that in the case of pyramidal cells sodium channels were blocked (in silico TTX application) when clamping above $-60 \mathrm{mV}$ to avoid spontaneous firing of the cell models (see Figure 5 in Migliore et al. (2018)). Thirdly, a spike from the presynaptic cell was triggered, which stimulated all the synapses of the connection and resulted in a somatic PSP of the postsynaptic neuron. This exercise was run for 50 pairs with 35 repetitions for each. Lastly, mean PSP amplitude was compared to the experimentally reported one and peak conductance value was adjusted respectively using the formula:

$$
\hat{g}=\hat{g} \frac{P S P_{\text {exp }}\left(1-P S P_{\text {model }}\right) / d f}{P S P_{\text {model }}\left(1-P S P_{\text {exp }}\right) / d f}
$$


where $P S P_{\text {exp }}(\mathrm{mV})$ and $P S P_{\text {model }}(\mathrm{mV})$ are the experimental and modeled PSPs amplitudes respectively and $d f=\left|E_{\text {rev }}-V_{\text {hold }}\right|(\mathrm{mV})$ is the driving force. $E_{r e v}=0 \mathrm{mV}$ was used for excitatory connections, while $E_{r e v}=-80 \mathrm{mV}$ for the inhibitory ones. All simulations were run using the NEURON simulator as a core engine (Hines and Carnevale, 1997) with the Blue Brain Project's collection of .hoc and NMODL (Hines and Carnevale, 2000) templates for parallel execution on supercomputers (Hines et al., 2008a,b).

\section{7 $\quad$ Statistical analysis}

$\mathrm{R}$ values for validating matching experimental and model values are Pearson correlations. Data are presented as mean \pm std to yield comparable values to the experimental ones.

\section{Results}

The unifying workflow used to integrate synaptic data about the hippocampal CA1 is presented in Figure 1 and results from our literature review, parameter fitting and modeling will be detailed step-by-step in the following sections.

\subsection{Literature curation}

Firstly, we undertook an extensive literature review of paired recording experiments, and compiled data on the various parameters (see Supplementary Table S1 for voltage clamp, and Supplementary Table S2 for current clamp recordings from rat hippocampal CA1). The data collected in this manner is sparse and inhomogeneous, due to the diversity of experimental conditions used by different labs and were corrected for various aspects. $\left[\mathrm{Ca}^{2+}\right]_{o}$ is known to affect release probability and additional Hill scaling had to be considered when parametrizing STP profiles (see Methods). Rise and decay time constants of synaptic currents are influenced by temperature differences but can be corrected with Q10 factors (see Methods). For electrophysiological recordings patch pipettes are becoming the standard practice over sharp electrodes nowadays, however, care should be taken when using absolute potentials reported from publications using whole-cell patch-clamp recordings (see Methods).

\subsection{Validation of synapse anatomy and dendritic attenuation}

Before we ran any simulations with synapses using the extracted parameters, we verified that the anatomy of synapses (Figure 2) such as the number of synapses per connection and targeting profile, as well as basic electrophysical properties of the cell models match experimental data. Cell pairs used in the simulations were pulled out from a data-driven reconstruction of the rat CA1 region, built with the pipeline presented in Markram et al. (2015). Number of synapses per connection for experimentally characterized pathways (Ali, 2011; Biro et al., 2005; Buhl et al., 1994a,b; Deuchars and Thomson, 1996; Földy et al., 2010; Maccaferri et al., 2000; Sik et al., 1995; Vida et al., 1998) ( $r=0.98$, Figure $2 \mathrm{~b}$ and Supplementary Table S3) along with targeting profile (Figure $2 \mathrm{a}$ ) was verified for this work. PSP attenuation in the active dendrites of PCs (Migliore et al., 2018) is also in line with the experimentally reported curves (Magee and Cook, 2000) (Supplementary Figure S1).

\subsection{Short-term plasticity of synapses}

Transmission properties of hippocampal CA1 neurons were demonstrated to express a wide range of STP profiles in response to presynaptic trains of action potentials at different frequencies (Ali 
et al., 1998, 1999; Ali and Thomson, 1998; Éltes et al., 2017; Kohus et al., 2016; Losonczy et al., 2002; Pouille and Scanziani, 2004). However, to our best knowledge, only Losonczy et al. (2002) and Kohus et al. (2016) reported TM model parameters for CA1 pathways and used additional recovery spike after the spike train, which is crucial to distinguish pseudo-linear profiles from purely facilitating or depressing ones. Published STP parameters from Losonczy et al. (2002) were used for PC to basket cell pathways, after refitting a subset of their data and confirming the similarity between our resulting $U_{S E}, D, F$ values. Kohus et al. (2016) also took the effort to make their raw traces publicly available, thus despite all the differences from our standard approach (current-clamp recordings from rat at $\left[\mathrm{Ca}^{2+}\right]_{o}=2 \mathrm{mM}$ ) we used their traces to fit the parameters (see Methods) of the TM model (Tsodyks and Markram, 1997; Markram et al., 1998). We rigorously validated that our event-based amplitude fitting is equivalent to the equations previously presented in the literature (Markram et al., 1998; Maass and Markram, 2002) (see Supplementary Methods). Fitted parameters matched well the ones fitted in the original article (Kohus et al., 2016), despite the slight differences in the TM model used, and the CVs of the first PSC amplitudes, which were not used during the fitting (see Methods) were also close to experimental ones $(r=0.8$, Figure $3 \mathrm{~b}$, Supplementary Table S4). (CCK + dendrite targeting interneurons were used as Schaffer collateral-associated cells.) For PV $+\mathrm{BC}$ to $\mathrm{PC}$ and $\mathrm{PV}+\mathrm{BC}$ we had to introduce MVR (see Methods) (with $N_{R R P}=6$ vesicles) to match the CVs of the measured PSCs (Figure $3 \mathrm{~b}$ ). On the other hand, in silico PV $+\mathrm{BC}$ to AA PSCs had lower CVs with UVR than the in vitro ones, which could not be corrected. (MVR can reduce the variance, but not increase). Biró et al. (2006) have shown in an elegant study, that while CCK+BC to PC connections in CA3 are characterized by MVR (with $N_{R R P}=5-7$ vesicles) under experimentally imposed high release probability conditions (high extracellular $\mathrm{Ca} / \mathrm{Mg}$ ratio), at physiologically relevant $\left[\mathrm{Ca}^{2+}\right]_{o}$ UVR is more prevalent. In our simulations, the $\mathrm{CV}$ of the in silico $\mathrm{CCK}+\mathrm{BC}$ to PC PSCs matched well the in vitro ones, recorded under physiological conditions using UVR, in good agreement with the Biró et al. (2006) study. For the remaining pathways $U_{S E}, D, F$ values from the analogous pathways of the somatosensory cortex (Markram et al., 2015) were used since parameters of the comparable connections matched well (perisomatic inhibitory to PC, inhibitory to inhibitory) and that is the most comprehensive dataset available to date. Based on the literature and our model-fitting we identified several rules to characterize and group STP profiles. The characterization of all pathways result as follows (Table 1, Figure 4): PC to O-LM cells (Ali and Thomson, 1998; Biro et al., 2005; Losonczy et al., 2002; Pouille and Scanziani, 2004) and other interneurons in stratum oriens (Éltes et al., 2017) E1 (excitatory facilitating). PC to PC (Deuchars and Thomson, 1996), PC to all SOM- interneurons (Ali et al., 1998; Losonczy et al., 2002; Pouille and Scanziani, 2004) E2 (excitatory depressing). CCK + interneurons to CCK + interneurons (Ali, 2007, 2011; Kohus et al., 2016) I1 (inhibitory facilitating), PV + and SOM+ interneurons to PC (Ali et al., 1998, 1999; Bartos et al., 2002; Buhl et al., 1995; Daw et al., 2009; Kohus et al., 2016; Maccaferri et al., 2000; Pawelzik et al., 2002) as well as interneurons to interneurons (except the CCK + ones) (Bartos et al., 2002; Daw et al., 2009; Elfant et al., 2008; Karayannis et al., 2010; Kohus et al., 2016; Price et al., 2005) I2 (inhibitory depressing). $\mathrm{CCK}+$ and NOS + (only Ivy cells, since we lack NGF morphologies) to PC (Fuentealba et al., 2008; Kohus et al., 2016; Price et al., 2008) I3 (inhibitory pseudo linear). It is important to note here that these profiles are valid in juvenile animals at $\left[\mathrm{Ca}^{2+}\right]_{o}=2 \mathrm{mM}$, but in some cases, release probability scales drastically with $\left[\mathrm{Ca}^{2+}\right]_{o}$ and the STP profiles can change as well. For example, at an in vivo like calcium level (1.1-1.3 $\mathrm{mM})$ the $\mathrm{PC}$ to $\mathrm{PC}$ pathway can show an E3 (excitatory pseudo-linear) characteristic with amplitudes having a lower mean and higher trial-by-trial variability and more failures compared to the in vitro $(2 \mathrm{mM})$ depressing E2 profile (Supplementary Figure $2 \mathrm{~b}$ ). As a function of $\left[\mathrm{Ca}^{2+}\right]_{o} U_{S E}$ values (absolute release probability parameter of the TM model) are scaled by Hill isotherm (see Methods) parametrized with cortical 
data of PSP amplitude changes (Supplementary Figure S11 in Markram et al. (2015)). Here we have shown that applying this scaling function on the absolute release probabilities indeed results in the same scaling profile of PSP amplitudes in the case of PC to PC connection (Supplementary Figure 2 a).

\subsection{Tuning of peak conductances to match PSP amplitudes}

Peak conductances of single synapses cannot be measured routinely with today's experimental techniques, thus are always somehow tuned to match a desired behavior in modeling studies. While it is appealing to calculate peak conductances from voltage-clamp recordings simply by dividing peak PSC amplitudes by the driving forces and plug them into a synapse model, it should not be done because of the space clamp artifacts (Bar-Yehuda and Korngreen, 2008; Spruston et al., 1993; Williams and Mitchell, 2008). Namely, if one voltage clamps the soma of a neuron, that will not necessarily mean that the dendritic compartments where most of the synapses arrive will have the same holding voltage (which cannot be compensated experimentally) and this can bias the driving force estimate. Furthermore, in the case of thin dendrites and strong synapses, the relation between the PSC amplitude and the peak conductance is rather sublinear (Gulyás et al., 2016). Using the same reasoning and access to connections measured in both voltage clamp and current clamp modes from the somatosensory cortex we have recently shown that the space clamp corrected in silico peak conductances are at least twice as big as their calculated counterparts (Markram et al., 2015). In the case of rat hippocampal CA1, we did not have the luxury of having both PSCs and PSPs from the same pair (See Supplementary Tables S1 and S2), thus just used all PSPs to tune the in silico peak conductances to match the in vitro PSPs (Ali et al., 1998; Ali and Thomson, 1998; Cobb et al., 1997; Deuchars and Thomson, 1996; Fuentealba et al., 2008; Pawelzik et al., 1999, 2002) (Figure 3 d, Table 1). In short, all other synapse parameters (anatomy, rise, and decay time constants, STP parameters, $N_{R R P}$, NMDA/AMPA peak conductance ratio, reversal potential) were rigorously validated, a pair was selected from the digitally reconstructed circuit, the postsynaptic neuron was current clamped to the given holding voltage, a spike was delivered from the presynaptic neuron, which caused a PSP, measured in the soma. After repeating this for multiple pairs $(n=50)$ with many trials for each $(n=35)$ we scaled the peak conductance to match the reference mean PSP amplitude (see Methods). Next, we repeated the same protocol on a different set of randomly selected 50 pairs with the tuned peak conductance distributions as a validation of the reconstruction process itself $(r=0.99$, Figure $3 \mathrm{~d}$, Supplementary Table S5). As an external validation of the resulting peak conductances, we set to compare them to published single-channel conductance and receptor number estimates. We only found sufficient data in the case of excitatory connections to PCs. CA1 PCs receive most of their excitatory inputs from CA3 PCs by the Schaffer collaterals (Megías et al., 2001; Takács et al., 2012), whereas in the present article we only considered internal connections (eg. excitatory connections between CA1s) and no long-range projections. Thus, single-channel conductance and receptor number estimates from the Schaffer collateral synapses were assumed to generalize for the internal PC to PC connections (Table 2). Using non-stationary fluctuation analysis on EPSCs recorded in outside-out dendritic membrane patches, Spruston et al. (1995) estimated $10.2 \mathrm{pS}$ AMPA and $43.5 \mathrm{pS}$ NMDA single-channel conductances. Using these numbers, our tuned $0.6 \pm 0.1 \mathrm{nS}$ AMPA peak conductance (Table 1 ) is the net result of $\sim 59$ AMPA and $\sim 18$ NMDA receptors (with 1.33 NMDA/AMPA peak conductance ratio, see Methods). In their in vitro study, Spruston et al. (1995) estimated 58-70 AMPA and 5-30 NMDA receptors (Jonas et al., 1993), which align well with our in silico predictions. MPA receptor numbers were also estimated with a quantitative immunogold localization technique (Nusser et al., 1998), as well as by non-stationary fluctuation analysis on single-spine level following two-photon glutamate uncaging (Matsuzaki et al., 2001) and these numbers also parallel with our predictions. Taken 
together, these data serve as an independent validation of the tuned peak conductance of the most important, PC to PC pathway. Predicted average GABA conductance is $1.8 \pm 0.6 \mathrm{nS}$, which corresponds to $\sim 90$ GABA receptors, which is also in good agreement with general estimates for the central nervous system (Mody and Pearce, 2004).

\subsection{Parameter generalization}

After integrating all the parameters (Table 1), obtaining values from somatosensory cortex to fill knowledge gaps when necessary (Table 1), and simulating paired recordings in silico we could extend predictions derived through this framework to other pathways (Figure $3 \mathrm{c}, \mathrm{e}$ ). Synapse anatomy of the experimentally uncharacterized pathways was assumed to be correct and missing kinetic parameters were filled in with average values from the known ones, grouped by neurochemical markers, targeting and STP profiles and peak conductances (Table 1). This exercise resulted in 9 classes, covering all connection types in the CA1 region (Table 1, Figure 4). All the assumptions used in this study leading to the set of presented model parameters are listed in Table 2. Among other values, we predicted the first PSP amplitudes of all possible connections (Figure 3 e), given our cell models (Migliore et al., 2018) and connectivity. An exemplar rare case of more than one published value for a given synaptic property in the literature is the notion of "strong" connection between PCs and CA1 interneurons (Gulyás et al., 1993), which could not be used directly for tuning because the postsynaptic target was not clear, but was confirmed after generalization and in silico experiments with all possible postsynaptic interneurons (Figure $3 \mathrm{e}$ ). It is important to note, that due to the highly detailed nature of our digital, data-driven reconstruction process not only mean pathway values (Figure $3 \mathrm{c}$, e) but also detailed distributions can be predicted with the framework (Figure $3 \mathrm{f}$ ).

\subsection{Synaptic strength}

It is general practice among modelers using simplified models to represent synapses as single contacts between neurons and parameterize them with a single "weight". It is important to note that in the detailed models presented here to concept of "weight" is a result of several features not just the peak conductance. This concept depends on the number and location of synapses (Figure 2 ), dendritic attenuation (Supplementary Figure S1), NMDA/AMPA conductance ratio and the interplay between release probability, number of vesicles and peak conductance. As an example, connections made by interneurons targeting perisomatic regions of PCs are mediated by multiple synapses with almost no attenuation, however have large peak conductances to compensate for the relatively low release probability (Table 1, Figure $4 \mathrm{~h}, \mathrm{i}$ ). They are characterized by low $U_{S E}$ values (in our stochastic model the release probability almost always equals $U_{S E}$ for depressing connections) and thus a high trial-to-trial variance. A notable exception from this high trial-totrial variance is the $\mathrm{PV}+\mathrm{BC}$ to $\mathrm{PC}$ pathway (Figure $3 \mathrm{a}, \mathrm{f}$ ), which is more reliable (Figure $3 \mathrm{f.6}$ ) thanks to the MVR with 6 independent synaptic vesicles per a single synapse.

\section{Discussion}

Recent advances in high-performance computing have enabled biologically detailed, data-driven reconstructions and large-scale simulations of brain regions (Bezaire and Soltesz, 2013; Bezaire et al., 2016; Markram et al., 2015; Wheeler et al., 2015). In the present study, we have demonstrated that a data-driven workflow grounded in biological first-principles, which was used to digitally reconstruct a biologically detailed model of rat neocortical tissue, can be extended to model other brain regions such as the hippocampal CA1, to reconcile disparate cellular and 
synaptic data, and to predictively extrapolate the sparse set of parameters to synaptic connections that have not yet been characterized experimentally. It is known that $\left[\mathrm{Ca}^{2+}\right]_{o}$ regulates the neurotransmitter release probability, and therefore, the amplitudes of PSPs. In this study we adapted the existing data-driven digital reconstruction workflow to reconcile differences in synaptic dynamics that were characterized at different levels of extracellular calcium. Therefore, we scaled the neurotransmitter release probabilities for all pathways that were characterized at 1.6-2 mM $\left[\mathrm{Ca}^{2+}\right]_{o}$ (Kohus et al., 2016; Losonczy et al., 2002; Markram et al., 2015) before tuning peak conductances to match PSP amplitudes that were measured at $2.5 \mathrm{mM}\left[\mathrm{Ca}^{2+}\right]_{o}$, which is more representative of baseline values for slice experiments (Ali et al., 1998; Ali and Thomson, 1998; Deuchars and Thomson, 1996; Fuentealba et al., 2008; Pawelzik et al., 1999, 2002).

In the continuing spirit of unifying hippocampal synaptic electrophysiology from published literature a recent complementary study leveraged text-mining techniques to extract the properties of synaptic connections in hippocampal CA1, including PSP amplitudes and peak conductances (Moradi and Ascoli, 2019). However, our approach to data integration from literature demonstrates that synaptic properties reported in the literature such as peak conductances should not be interpreted on face value but require further corrections to account for inadequate space-clamp errors, which could severely underestimate their value by two-three fold (Markram et al., 2015).

The results we report, to the best of our knowledge, constitute a comprehensive resource for not only for the anatomy but also the kinetic and short-term dynamic physiological properties of the rat hippocampal CA1 region. Consolidation of the state of the literature not only facilitates building detailed models, but also highlights knowledge gaps and could help in prioritizing the identification of missing data on CA1 connections, such as PC to interneurons, and between interneurons, which are key building blocks of feedback inhibition. Indeed, the parameter set presented here should be considered a first draft, which will be systematically refined as and when new experimental data become available. By detailing all the integration steps in this study, we had two main objectives. First, we aimed to demonstrate that published parameters should not be taken at face value without rigorously checking their consistency within any modeling framework, and the necessity of being abreast of the state-of-the-art experimental techniques. Second, we attempted to emphasize the fact that a growing diversity of experimental standards combined with published literature that provides access to only processed data sets but not raw experimental traces could lead to an inconsistent picture of a fundamental mechanism such as synaptic transmission. The bottom-up modeling framework presented as a resource in this article could enable ways to integrate disparate data and provide a platform in catalyzing communitydriven consensus on the synaptic organization of the hippocampal formation.

\section{Acknowledgements}

We would like to thank Giuseppe Chindemi, Natali Barros-Zulaica, Rodrigo Perin and Zoltán Nusser for fruitful discussions as well as Werner Van Geit, Michael Gevaert, Arseniy Povolotsky, Cyrille Favreau and Marwan Abdellah for technical assistance. An initial version of this manuscript was submitted to bioRxiv.

\section{Author contribution}

S.R., E.M. and A.R. conceptualized and supervised the study. S.K., M.M., A.M. and H.M. contributed to the supervision of the study. A.R. built the CA1 circuit with inputs from all authors. S.S. validated PSP attenuation. A.E. curated literature, performed simulations, analysis and created the figures with inputs from S.R. A.E. and S.R. wrote the manuscript with inputs from all authors. 


\section{Funding}

411 The ETH Domain for the Blue Brain Project (BBP); The Human Brain Project through the European 412 Union Seventh Framework Program (FP7/2007-2013) under grant agreement no. 604102 (HBP) and 413 from the European Union H2020 FET program through grant agreement no. 720270 (HBP SGA1); The 414 Cajal Blue Brain Project (MINECO); The BlueBrain V. HPE SGI 8600 system is financed by ETH 415 Board Funding to the Blue Brain Project as a National Research Infrastructure and hosted at the Swiss 416 National Supercomputing Center (CSCS).

\section{Conflict of interest}

418 The authors declare that the research was conducted in the absence of any commercial or financial 419 relationships that could be construed as a potential conflict of interest. 


\section{Tables}

Table 1: Parameters and generalization to 9 classes. Table with model synapse parameters either extracted from the literature $\left(\tau_{d}(\mathrm{~ms})\right)$, fitted $\left(U_{S E}, D(\mathrm{~ms}), F(\mathrm{~ms})\right)$, tuned $(\hat{g}(\mathrm{nS}))$ or taken from the somatosensory cortex (marked with*) (Markram et al., 2015). Average class parameters are marked in bold and are used predictively for the remaining pathways belonging to the same class. Abbreviations are as in Figure $\mathbf{2} \mathbf{b}$

\begin{tabular}{|c|c|c|c|c|c|c|c|}
\hline Pre & Post & $\hat{g}$ & $\tau_{d}$ & $U_{S E}$ & $D$ & $F$ & $N_{R R P}$ \\
\hline \multicolumn{8}{|c|}{$\mathrm{PC}$ to $\mathrm{PC}(\mathrm{E} 2)$} \\
\hline $\mathrm{PC}$ & $\mathrm{PC}$ & $0.6 \pm 0.1$ & $3 \pm 0.2$ & $0.5 \pm 0.02^{*}$ & $671 \pm 17^{*}$ & $17 \pm 5^{*}$ & 2 \\
\hline \multicolumn{8}{|c|}{$\mathrm{PC}$ to $\mathrm{SOM}+(\mathrm{E} 1)$} \\
\hline PC & $\mathrm{SOM}+$ & $0.85 \pm 0.1$ & $1.7 \pm 0.14^{*}$ & $0.09 \pm 0.12^{*}$ & $138 \pm 211^{*}$ & $670 \pm 830^{*}$ & 1 \\
\hline \multicolumn{8}{|c|}{ PC to SOM- (E2) } \\
\hline $\mathrm{PC}$ & PVBC & $3 \pm 0.3$ & $4.12 \pm 0.5$ & $0.23 \pm 0.09$ & $410 \pm 190$ & $10 \pm 11$ & 1 \\
\hline $\mathrm{PC}$ & $\mathrm{CCKBC}$ & $3.8 \pm 0.3$ & $4.12 \pm 0.5$ & $0.23 \pm 0.09$ & $410 \pm 190$ & $10 \pm 11$ & 1 \\
\hline $\mathrm{PC}$ & $\mathrm{BS}$ & $1.4 \pm 0.1$ & $4.12 \pm 0.5$ & $0.23 \pm 0.09$ & $410 \pm 190$ & $10 \pm 11$ & 1 \\
\hline $\mathrm{PC}$ & Ivy & $5 \pm 0.5$ & $4.12 \pm 0.5$ & $0.23 \pm 0.09$ & $410 \pm 190$ & $10 \pm 11$ & 1 \\
\hline PC & SOM- & $3.3 \pm 1.3$ & $4.12 \pm 0.5$ & $0.23 \pm 0.09$ & $410 \pm 190$ & $10 \pm 11$ & 1 \\
\hline \multicolumn{8}{|c|}{$\mathrm{PV}+$ to $\mathrm{PC}(\mathrm{I} 2)$} \\
\hline PVBC & $\mathrm{PC}$ & $1.75 \pm 0.1$ & $5.45 \pm 0.5$ & $0.16 \pm 0.02$ & $965 \pm 185$ & $8.6 \pm 4.3$ & 6 \\
\hline $\mathrm{AA}$ & $\mathrm{PC}$ & $2.35 \pm 0.2$ & $6.1 \pm 0.68$ & $0.1 \pm 0.01$ & $1278 \pm 760$ & $10 \pm 6.7$ & 1 \\
\hline BS & $\mathrm{PC}$ & $2.4 \pm 0.3$ & $6.81 \pm 0.42$ & $0.13 \pm 0.03$ & $1122 \pm 156$ & $9.3 \pm 0.7$ & 1 \\
\hline $\mathbf{P V}+$ & $\mathbf{P C}$ & $2.15 \pm 0.3$ & $6.1 \pm 0.68$ & $0.13 \pm 0.03$ & $1122 \pm 156$ & $9.3 \pm 0.7$ & 1 \\
\hline \multicolumn{8}{|c|}{$\mathrm{CCK}+$ to PC (I3) } \\
\hline CCKBC & $\mathrm{PC}$ & $1.7 \pm 0.3$ & $6.5 \pm 0.3$ & $0.16 \pm 0.04$ & $153 \pm 120$ & $12 \pm 3.5$ & 1 \\
\hline SCA & $\mathrm{PC}$ & $2.25 \pm 0.3$ & $8.3 \pm 0.44$ & $0.15 \pm 0.03$ & $185 \pm 32$ & $14 \pm 5.8$ & 1 \\
\hline $\mathbf{C C K}+$ & PC & $\mathbf{1 . 9} \pm \mathbf{0 . 2 7}$ & $7.5 \pm 0.9$ & $0.16 \pm 0.01$ & $168 \pm 15$ & $\mathbf{1 3} \pm \mathbf{0 . 5}$ & 1 \\
\hline \multicolumn{8}{|c|}{$\mathrm{SOM}+$ to $\mathrm{PC}(\mathrm{I} 2)$} \\
\hline Tri & $\mathrm{PC}$ & $1.3 \pm 0.3$ & $7.75 \pm 0.9$ & $0.3 \pm 0.08^{*}$ & $1250 \pm 520^{*}$ & $2 \pm 4^{*}$ & 1 \\
\hline SOM+ & $\mathrm{PC}$ & $1.3 \pm 0.3$ & $8.3 \pm 2.2^{*}$ & $0.3 \pm 0.08^{*}$ & $1250 \pm 520^{*}$ & $2 \pm 4^{*}$ & 1 \\
\hline \multicolumn{8}{|c|}{$\mathrm{NOS}+$ to PC (I3) } \\
\hline Ivy & $\mathrm{PC}$ & $0.55 \pm 0.05$ & $8.3 \pm 2.2^{*}$ & $0.32 \pm 0.14^{*}$ & $144 \pm 80^{*}$ & $62 \pm 31^{*}$ & 1 \\
\hline \multicolumn{8}{|c|}{ I to I (I2) } \\
\hline PVBC & PVBC & $2.2 \pm 0.3$ & $2.67 \pm 0.13$ & $0.26 \pm 0.05$ & $930 \pm 360$ & $1.6 \pm 0.6$ & 6 \\
\hline PVBC & $\mathrm{AA}$ & $2.2 \pm 0.3$ & $2.67 \pm 0.13$ & $0.24 \pm 0.15$ & $1730 \pm 530$ & $3.5 \pm 1.5$ & 1 \\
\hline I & $\mathbf{I}$ & $2.2 \pm 0.3$ & $2.67 \pm 0.13$ & $0.26 \pm 0.05$ & $930 \pm 360$ & $1.6 \pm 0.6$ & 1 \\
\hline \multicolumn{8}{|c|}{$\mathrm{CCK}+$ to $\mathrm{CCK}+(\mathrm{I} 1)$} \\
\hline CCKBC & CCKBC & $2.2 \pm 0.3$ & $4.5 \pm 0.55$ & $0.11 \pm 0.03$ & $115 \pm 110$ & $1542 \pm 700$ & 1 \\
\hline $\mathrm{SCA}$ & SCA & $2.2 \pm 0.3$ & $4.5 \pm 0.55$ & $0.11 \pm 0.03$ & $115 \pm 110$ & $1542 \pm 700$ & 1 \\
\hline
\end{tabular}


Table 2: List of assumptions. All the assumptions that were made to arrive at model parameters from a sparse set of raw data and published values.

1 When using data from Kohus et al. (2016) we assumed that CCK+DTI neurons are SCA cells in SR. Furthermore, we assumed that synaptic currents measured in mouse CA3 are representative for similar pathways in rat CA1.

2 We assume that after all the listed correction in this paper, all parameters coming from different sources can be used together to parameterize the synapse models.

3 In lack of data, we assumed that NMDA/AMPA peak current ratio for excitatory to excitatory connections can be used for excitatory to inhibitory connections as well.

4 Also in the lack of representative data and our lack of neurogliaform cells we assumed that all inhibitory synapses are mediated purely by $G A B A_{A}$ receptors.

5 For parametrizing reversal potentials we assumed that the general values of $0 \mathrm{mV}$ for excitatory and $-80 \mathrm{mV}$ for inhibitory synapses can be used for all pathways.

6 For calculating release probabilities at different extracellular calcium concentrations we assumed that Hill functions parameterized with cortical data generalize well for hippocampal connections.

7 For modeling synaptic currents, we assumed that all CA1 synapses can be described with double exponential conductances, with vesicle release kinetics governed by the TM model.

8 The synapse model presented here, does not account for any type of long-term changes.

9 The biggest assumptions are inherited from the network model: In this work, we assumed that the published electrical models of single cells (Migliore et al., 2018) capture the behavior of different neurons in rat CA1. (The fact that we can not clamp PC models to potentials above $-60 \mathrm{mV}$ without blocking sodium channels seems to violate this assumption.) We also assumed that the cell composition and cell density within the layers are homogeneous and the constrained connectivity reflects the connectivity of rat CA1.

10 An inherited assumption from Markram et al. (2015) is that the rise time constant of all synaptic currents is $0.2 \mathrm{~ms}$.

11 Kinetic parameters for a given pathway are drawn from a distribution, but since (almost) all experimental data used to derive these parameters are representative for a given connection and not for individual synapses per se, we use the same parameters for all synapses mediating a single connection.

12 When generalizing our parameters for similar, experimentally uncharacterized pathways we group CA1 interneurons based on only one chemical marker. However, cells express many of these and the markers overlap (see hippocampome.org (Wheeler et al., 2015)). By PV + cells we mean: SP_PVBCs, SP_BS cells and SP_AA cells. By CCK + cells we mean: SP_CCKBCs, SR_SCA cells and SLM_PPA cells. The only interneurons in our NOS+ class are SP__ Ivy cells. (Neurogliaform cells would belong here as well.) We assume all neurons in SO: SO_ŌLM cells, SO_BS cells, SO_Tri cells and SO_BP cells to be $\mathrm{SOM}+$.

13 A usually unspoken, implicit assumption on communication between neurons is used here as well, namely, we model only glutamatergic and GABAergic synapses between presynaptic axons and postsynaptic somas and dendrites. Thus, we leave out co-transmission and neuromodulators acting on different receptors, retrograde messengers, any kind of gap-junctions and any axonal receptors. 
bioRxiv preprint doi: https://doi.org/10.1101/716480; this version posted July 26, 2019. The copyright holder for this preprint (which was not certified by peer review) is the author/funder. All rights reserved. No reuse allowed without permission.

Ecker et al.

Integration of CA1 synapse physiology in silico

\section{Figure captions}

Figure 1. In silico data integration pipeline. 1: More than a hundred publications were used to compile data on various parameters of connected neurons in rat CA1. 2: Parameters were integrated into a common framework and experimental paradigm, including temperature, $\left[\mathrm{Ca}^{2+}\right]_{o}$ and LJP corrections. TM models of STP were fit to publicly available raw traces. 3: In silico paired recordings were run to correctly estimate the unitary peak conductance of connections with experimentally characterized PSP amplitudes. 4: Parameters were averaged within classes and used predictively to describe experimentally uncharacterized pathways.

Figure 2. In silico synapse anatomy. a: A representative in silico O-LM (purple) to PC (blue) pair, with synapses visualized in red. 3D morphologies were reconstructed with the Neurolucida software (Migliore et al., 2018) by the members of Alex Thomson's lab at UCL. a.1: Branch order distribution $(\mathrm{n}=5000$ connections) of the presynaptic (O-LM) axons. a.2: Branch order distribution of the postsynaptic (PC) tuft dendrites. a.3: Distribution of the number of synapses per connection of the in silico O-LM to PC pathway. In vitro experimental data is indicated in red. a.4: Distance dependent connection probability of the in silico O-LM to PC pathway. b: Validation of the number of synapses per connection against experimental data. (E: excitatory, I: inhibitory, eg.: I-E: inhibitory to excitatory pathways.) c: Predicted mean number of synapses per connections (within $200 \mu \mathrm{m}$ intersomatic distance) for all pathways in the CA1 network model. Layer abbreviations: SR: stratum radiatum, SP: stratum pyramidale, SO: stratum oriens. M-type (morphological type) abbreviations: AA: axo-axonic cell, BP: back-projecting cell, BS: bistratified cell, CCKBC: CCK + basket cell, Ivy: ivy cell, OLM: oriens-lacunosum moleculare cell, PC: pyramidal cell, PVBC: PV + basket cell, PPA: performant path-associated cell, SCA: Schaffer collateral-associated cell, Tri: trilaminar cell. d: Predicted mean connection probability (within $200 \mu \mathrm{m}$ intersomatic distance) for all pathways in the CA1 network model. M-type abbreviations are as in c.

Figure 3. In silico synapse physiology. a: In silico paired recording experiment with the STP protocol used in Kohus et al. (2016). Presynaptic $(\mathrm{PV}+\mathrm{BC})$ voltage trace is shown on top. In silico $\mathrm{PV}+\mathrm{BC}$ (green) to PC (blue) pair, with synapses visualized in red in the middle. 3D morphologies were reconstructed with the Neurolucida software (Migliore et al., 2018) by the members of Alex Thomson's lab at UCL. Postsynaptic (PC) experimental traces recorded in vitro (in gray) and their mean in red, as well as model traces recorded in silico (in gray) and their mean in blue, are presented at the bottom panel. Insets show the variance of the first IPSCs. b: Validation of the CV of the first PSC amplitudes against experimental data. (E: excitatory, I: inhibitory, eg.: I-E: inhibitory to excitatory pathways.) c: Predicted CVs of first PSC amplitudes for all pathways in the CA1 network model after synapse parameter generalization. 20 pairs with 35 repetitions for every possible connection. Postsynaptic cells were held at $-65 \mathrm{mV}$ in in silico voltage-clamp mode. M-type abbreviations are as in Figure 2 b. d: Validation of the PSP amplitudes against experimental data. (E: excitatory, I: inhibitory, eg.: I-E: inhibitory to excitatory pathways.) e: Predicted PSP amplitudes for all pathways in the CA1 network model after synapse parameter generalization. 20 pairs with 35 repetitions for every possible connection. Postsynaptic cells were held at $-65 \mathrm{mV}$ in in silico current-clamp mode. M-type abbreviations are as in Figure 2 b. f: Properties of postsynaptic (PC) IPSPs. f.1: Distribution of in silico PSP amplitudes. In vitro experimental data is indicated in red. f.2: Distribution of in silico PSP 10-90\% rise times. f.3: Distribution of in silico PSP decay time constants. f.4: Distribution of in silico PSP latencies. f.5: Distribution of the CVs of the first in silico PSP amplitudes. f.6: Distribution of in silico failure rates.

Figure 4. Summary of synapse diversity in the CA1 network model. Panels represent exemplar in silico pairs from the 9 generalized pathways (2 for PC to SOM- interneurons). Presynaptic voltage traces are shown on the top of the panels, while 35 repetitions (in gray) and their mean postsynaptic PSPs are presented on the bottom of the panels for each pathway. Postsynaptic cells were held at $-65 \mathrm{mV}$ in in silico current-clamp mode. a: PC to PC (E2). b: PC to O-LM cell (E1). c: PC to bistratified cell (E2). d: $\mathrm{PC}$ to $\mathrm{CCK}+\mathrm{BC}(\mathrm{E} 2)$. e: $\mathrm{O}-\mathrm{LM}$ cell to $\mathrm{PC}(\mathrm{I} 2)$. f: $\mathrm{CCK}+\mathrm{BC}$ to $\mathrm{CCK}+\mathrm{BC}$ (I1). g: Ivy cell to $\mathrm{PC}(\mathrm{I} 3)$. h: $\mathrm{CCK}+\mathrm{BC}$ to $\mathrm{PC}(\mathrm{I} 3)$. i: $\mathrm{PV}+\mathrm{BC}$ to $\mathrm{PC}(\mathrm{I} 2)$. j: $\mathrm{PV}+\mathrm{BC}$ to $\mathrm{PV}+\mathrm{BC}$ (I2). Connectivity in the schematic CA1 microcircuit in the middle is simplified for visualization purpose (for example most of the interneuron to interneuron connections are missing). Simplified synapses of the pathways shown in the panels around are indicated with gray circles. M-type abbreviations are as in Figure 2 b. 


\section{References}

Ali, A. B. (2007). Presynaptic Inhibition of GABAA Receptor-Mediated Unitary IPSPs by Cannabinoid Receptors at Synapses Between CCK-Positive Interneurons in Rat Hippocampus. Journal of Neurophysiology, 98(2):861-869.

Ali, A. B. (2011). CB1 modulation of temporally distinct synaptic facilitation among local circuit interneurons mediated by N-type calcium channels in CA1. Journal of Physiology, 105:1051-1062.

Ali, A. B., Bannister, A. P., and Thomson, A. M. (1999). IPSPs elicited in CA1 pyramidal cells by putative basket cells in slices of adult rat hippocampus. European Journal of Neuroscience, 11(5):1741-1753.

Ali, A. B., Deuchars, J., Pawelzik, H., and Thomson, A. M. (1998). CA1 pyramidal to basket and bistratified cell EPSPs: Dual intracellular recordings in rat hippocampal slices. Journal of Physiology, 507(1):201-217.

Ali, A. B. and Thomson, A. M. (1998). Facilitating pyramid to horizontal oriens-alveus interneurone inputs: Dual intracellular recordings in slices of rat hippocampus. Journal of Physiology, 507(1):185199.

Andrasfalvy, B. K. and Magee, J. C. (2001). Distance-dependent increase in AMPA receptor number in the dendrites of adult hippocampal CA1 pyramidal neurons. The Journal of Neuroscience, 21(23):91519159 .

Bar-Yehuda, D. and Korngreen, A. (2008). Space-Clamp Problems When Voltage Clamping Neurons Expressing Voltage-Gated Conductances. Journal of Neurophysiology, 99(3):1127-1136.

Barros-Zulaica, N., Rahmon, J., Chindemi, G., Perin, R., Markram, H., Ramaswamy, S., and Muller, E. (2019). Estimating the Readily-Releasable Vesicle Pool Size at Synaptic Connections in a Neocortical Microcircuit. bioRxiv.

Bartos, M., Vida, I., Frotscher, M., Meyer, A., Monyer, H., Geiger, J. R. P., and Jonas, P. (2002). Fast synaptic inhibition promotes synchronized gamma oscillations in hippocampal interneuron networks. PNAS, 99(20):13222-13227.

Bezaire, M. J., Raikov, I., Burk, K., Vyas, D., and Soltesz, I. (2016). Interneuronal mechanisms of hippocampal theta oscillations in a full-scale model of the rodent CA1 circuit. eLife, 5(e18566):1-106.

Bezaire, M. J. and Soltesz, I. (2013). Quantitative assessment of CA1 local circuits: Knowledge base for interneuron-pyramidal cell connectivity. Hippocampus, 23(9):751-785.

Bibbona, E., Panfilo, G., and Tavella, P. (2008). The Ornstein-Uhlenbeck process as a model of a low pass filtered white noise. Meterologia, 45(6):S117.

Biro, A. A., Holderith, N. B., and Nusser, Z. (2005). Quantal Size Is Independent of the Release Probability at Hippocampal Excitatory Synapses. Journal of Neuroscience, 25(1):223-232.

Biró, A. A., Holderith, N. B., and Nusser, Z. (2006). Release probability-dependent scaling of the postsynaptic responses at single hippocampal GABAergic synapses. The Journal of neuroscience, 26(48):12487-96.

Bliss, T. V. and Collingridge, G. L. (2013). Expression of NMDA receptor-dependent LTP in the hippocampus: bridging the divide. Molecular Brain, 6(5).

Buhl, E. H., Cobb, S. R., Halasy, K., and Somogyi, P. (1995). Properties of unitary IPSPs evoked by anatomically identified basket cells in the rat hippocampus. European Journal of Neuroscience, 7(9):1989-2004.

Buhl, E. H., Halasy, K., and Somogyi, P. (1994a). Diverse sources of hippocampal unitary inhibitory postsynaptic potentials and the number of synaptic release sites. Nature, 368:823-828. 
Buhl, E. H., Han, Z.-S., Lörinczi, Z., Stezhka, V. V., Karnup, S. V., and Somogyi, P. (1994b). Physiological Properties of Anatomically Identified AxoAxonic in the Rat Hippocampus. Journal of Neurophysiology, 71(4):1289-1307.

Buzsáki, G. (1989). Two-stage model of memory trace formation: A role for "noisy" brain states. Neuroscience, 31(3):551-570.

Chindemi, G. (2018). Towards a unified understanding of synaptic plasticity: parsimonious modeling and simulation of the glutamatergic synapse life-cycle. PhD thesis, EPFL.

Christie, J. M. and Jahr, C. E. (2006). Multivesicular Release at Schaffer Collateral-CA1 Hippocampal Synapses. Journal of Neuroscience, 26(1):210-216.

Cobb, S. R., Halasy, K., Vida, I., Nyíri, G., Tamás, G., Buhl, E. H., and Somogyi, P. (1997). Synaptic effects of identified interneurons innervating both interneurons and pyramidal cells in the rat hippocampus. Neuroscience, $79(3): 629-648$.

Conti, R. and Lisman, J. (2003). The high variance of AMPA receptor- and NMDA receptor-mediated responses at single hippocampal synapses: Evidence for multiquantal release. PNAS, 100(8):4885-4890.

Daw, M. I., Tricoire, L., Erdelyi, F., Szabo, G., and McBain, C. J. (2009). Asynchronous Transmitter Release from Cholecystokinin-Containing Inhibitory Interneurons Is Widespread and Target-Cell Independent. Journal of Neuroscience, 29(36):11112-11122.

Del Castillo, J. and Katz, B. (1954). Quantal components of the end-plate potential. The Journal of Physiology, 124(3):560-573.

Deuchars, J. and Thomson, A. M. (1996). CA1 pyramid-pyramid connections in rat hippocampus in vitro: Dual intracellular recordings with biocytin filling. Neuroscience, 74(4):1009-1018.

Elfant, D., Pal, B. Z., Emptage, N., and Capogna, M. (2008). Specific inhibitory synapses shift the balance from feedforward to feedback inhibition of hippocampal CA1 pyramidal cells. European Journal of Neuroscience, 27(1):104-113.

Éltes, T., Kirizs, T., Nusser, Z., and Holderith, N. (2017). Target Cell Type-Dependent Differences in $\mathrm{Ca} 2+$ Channel Function Underlie Distinct Release Probabilities at Hippocampal Glutamatergic Terminals. The Journal of Neuroscience, 37(7):1910-1924.

Földy, C., Lee, S.-h., Morgan, R. J., and Soltesz, I. (2010). Regulation of fast-spiking basket cell synapses by the chloride channel ClC-2. Nature Neuroscience, 13(9):1047-1049.

Fuentealba, P., Begum, R., Capogna, M., Jinno, S., Márton, L. F., Csicsvari, J., Thomson, A., Somogyi, P., and Klausberger, T. (2008). Ivy Cells: A Population of Nitric-Oxide-Producing, Slow-Spiking GABAergic Neurons and Their Involvement in Hippocampal Network Activity. Neuron, 57(6):917929.

Fuhrmann, G., Segev, I., Markram, H., and Tsodyks, M. (2002). Coding of Temporal Information by Activity-Dependent Synapses. Journal of Neurophysiology, 87(1):140-148.

Groc, L., Gustafsson, B., and Hanse, E. (2002). Spontaneous unitary synaptic activity in CA1 pyramidal neurons during early postnatal development: constant contribution of AMPA and NMDA receptors. The Journal of Neuroscienceeuroscience, 22(13):5552-5562.

Gulyás, A. I., Freund, T. F., and Káli, S. (2016). The Effects of Realistic Synaptic Distribution and 3D Geometry on Signal Integration and Extracellular Field Generation of Hippocampal Pyramidal Cells and Inhibitory Neurons. Frontiers in Neural Circuits, 10(88).

Gulyás, a. I., Miles, R., Sík, A., Tóth, K., Tamamaki, N., and Freund, T. F. (1993). Hippocampal pyramidal cells excite inhibitory neurons through a single release site. Nature, 366:683-687. 
Hestrin, S., Sah, P., and Nicoll, R. A. (1990). Mechanisms Generating the Time Course of Dual Component Excitatory Synaptic Currents Recorded in Hippocampal Slices. Neuron, 5:247-253.

Hill, A. V. (1910). The possible effects of the aggregation of the molecules of haemoglobin on its dissociation curves. Journal of Physiology, 40:4-7.

Hines, M. L. and Carnevale, N. T. (1997). The NEURON simulation environment. Neural computation, 9(6):1179-1209.

Hines, M. L. and Carnevale, N. T. (2000). Expanding NEURON's repertoire of mechanisms with NMODL. Neural Computation, 12(5):995-1007.

Hines, M. L., Eichner, H., and Schürmann, F. (2008a). Neuron splitting in compute-bound parallel network simulations enables runtime scaling with twice as many processors. Journal of computational neuroscience, 25(1):203-210.

Hines, M. L., Markram, H., and Schürmann, F. (2008b). Fully implicit parallel simulation of single neurons. Journal of computational neuroscience, 25(3):439-448.

Jahr, C. E. and Stevens, C. F. (1990). Voltage dependence of NMDA-activated macroscopic conductances predicted by single-channel kinetics. The Journal of neuroscience, 10(9):3178-3182.

Jonas, P., Major, G., and Sakmann, B. (1993). Quantal components of unitary EPSCs at the mossy fibre synapse on CA3 pyramidal cells of rat hippocampus. The Journal of Physiology, 472:615-663.

Karayannis, T., Elfant, D., Huerta-Ocampo, I., Teki, S., Scott, R. S., Rusakov, D. A., Jones, M. V., and Capogna, M. (2010). Slow GABA transient and receptor desensitization shape synaptic responses evoked by hippocampal neurogliaform cells. The Journal of neuroscience, 30(29):9898-909.

Kohus, Z., Káli, S., Schlingloff, D., Papp, O., Rovira-Esteban, L., Freund, T. F., Hájos, N., and Gulyás, A. I. (2016). Properties and dynamics of inhibitory synaptic communication within the CA3 microcircuits of pyramidal cells and interneurons expressing parvalbumin or cholecystokinin. The Journal of physiology, 594(13):3745-74.

Korinek, M., Sedlacek, M., Cais, O., Dittert, I., and Vyklicky, L. (2010). Temperature dependence of N-methyl-d-aspartate receptor channels and N-methyl-d-aspartate receptor excitatory postsynaptic currents. Neuroscience, 165(3):736-748.

Loebel, A., Silberberg, G., Helbig, D., Markram, H., Tsodyks, M., and Richardson, M. J. E. (2009). Multiquantal release underlies the distribution of synaptic efficacies in the neocortex. Frontiers in Cellular Neuroscience, 3(27).

Losonczy, A., Zhang, L., Shigemoto, R., Somogyi, P., and Nusser, Z. (2002). Cell type dependence and variability in the short-term plasticity of EPSCs in identified mouse hippocampal interneurones. The Journal of physiology, 542(1):193-210.

Maass, W. and Markram, H. (2002). Synapses as dynamic memory buffers. Neural Networks, 15(2):155161.

Maccaferri, G., Roberts, J. D. B., Szucs, P., Cottingham, C. A., and Somogyi, P. (2000). Cell surface domain specific postsynaptic currents evoked by identified GABAergic neurones in rat hippocampus in vitro. Journal of Physiology, 524(1):91-116.

Magee, J. C. and Cook, E. P. (2000). Somatic EPSP amplitude is independent of synapse location in hippocampal pyramidal neurons. Nature neuroscience, 3(9):895-903.

Markram, H., Wang, Y., and Tsodyks, M. (1998). Differential signaling via the same axon of neocortical pyramidal neurons. PNAS, 95(9):5323-8.

Markram, M., Muller, E., Ramaswamy, S., Reimann, M. W., et al. (2015). Reconstruction and Simulation of Neocortical Microcircuitry. Cell, 163:456-492. 
Matsuzaki, M., Ellis-Davies, G. C., Nemoto, T., Miyashita, Y., Iino, M., and Kasai, H. (2001). Dendritic spine geometry is critical for AMPA receptor expression in hippocampal CA1 pyramidal neurons. Nature Neuroscience, 4(11):1086-1092.

Megías, M., Emri, Z., Freund, T. F., and Gulyás, a. I. (2001). Total number and distribution of inhibitory and excitatory synapses on hippocampal CA1 pyramidal cells. Neuroscience, 102(3):527-540.

Migliore, R., Lupascu, C. A., Bologna, L. L., Romani, A., Courcol, J.-D., Antonel, S., Van Geit, W. A. H., Thomson, A. M., Mercer, A., Lange, S., Falck, J., Rössert, C. A., Shi, Y., Hagens, O., Pezzoli, M., Freund, T. F., Kali, S., Muller, E. B., Schürmann, F., Markram, H., and Migliore, M. (2018). The physiological variability of channel density in hippocampal CA1 pyramidal cells and interneurons explored using a unified data-driven modeling workflow. PLOS Computational Biology, 14(9):e1006423.

Mody, I. and Pearce, R. A. (2004). Diversity of inhibitory neurotransmission through GABA A receptors. Trends in Neurosciences, 27(9):569-575.

Moradi, K. and Ascoli, G. A. (2019). A comprehensive knowledge base of synaptic electrophysiology in the rodent hippocampal formation. bioRxiv, page http://doi.org/10.1101/632760.

Myme, C. I. O., Sugino, K., Turrigiano, G. G., and Nelson, S. B. (2003). The NMDA-to-AMPA Ratio at Synapses Onto Layer 2/3 Pyramidal Neurons Is Conserved Across Prefrontal and Visual Cortices. Journal of Neurophysiology, 90(2):771-779.

Neher, E. (1992). Correction for liquid junction potentials in patch clamp experiments. Methods in Enzymology, 207:123-131.

Nusser, Z., Lujan, R., Laube, G., Roberts, J. D. B., Molnar, E., and Somogyi, P. (1998). Cell type and pathway dependence of synaptic AMPA receptor number and variability in the hippocampus. Neuron, 21(3):545-559.

Pawelzik, H., Bannister, A. P., Deuchars, J., Ilia, M., and Thomson, A. M. (1999). Modulation of bistratified cell IPSPs and basket cell IPSPs by pentobarbitone sodium, diazepam and Zn2+: Dual recordings in slices of adult rat hippocampus. European Journal of Neuroscience, 11(10):3552-3564.

Pawelzik, H., Hughes, D. I., and Thomson, A. M. (2002). Physiological and morphological diversity of immunocytochemically defined parvalbumin- and cholecystokinin-positive interneurones in CA1 of the adult rat hippocampus. Journal of Comparative Neurology, 443(4):346-367.

Pouille, F. and Scanziani, M. (2004). Routing of spike series by dynamic circuits in the hippocampus. Nature, 429(6993):717-723.

Price, C. J., Cauli, B., Kovács, E. R., Kukik, Á., Lambolez, B., Shigemeto, R., and Capogna, M. (2005). Neurogliaform Neurons Form a Novel Inhibitory Network in the Hippocampal CA1 Area. Journal of Neuroscience, 25(29):6775-6786.

Price, C. J., Scott, R., Rusakov, D. A., and Capogna, M. (2008). GABAB Receptor Modulation of Feedforward Inhibition through Hippocampal Neurogliaform Cells. The Journal of Neuroscience, 28(27):6974-6982.

Ramaswamy, S., Courcol, J.-D., Abdellah, M., Adaszewski, S. R., Antille, N., Arsever, S., Atenekeng, G., Bilgili, A., Brukau, Y., Chalimourda, A., Chindemi, G., Delalondre, F., Dumusc, R., Eilemann, S., Gevaert, M. E., Gleeson, P., Graham, J. W., Hernando, J. B., Kanari, L., Katkov, Y., Keller, D., King, J. G., Ranjan, R., Reimann, M. W., Rössert, C., Shi, Y., Shillcock, J. C., Telefont, M., Van Geit, W., Villafranca Diaz, J., Walker, R., Wang, Y., Zaninetta, S. M., DeFelipe, J., Hill, S. L., Muller, J., Segev, I., Schürmann, F., Muller, E. B., and Markram, H. (2015). The neocortical microcircuit collaboration portal: a resource for rat somatosensory cortex. Frontiers in Neural Circuits, 9(44).

Ramaswamy, S., Hill, S. L., King, J. G., Schürmann, F., Wang, Y., and Markram, H. (2012). Intrinsic morphological diversity of thick-tufted layer 5 pyramidal neurons ensures robust and invariant properties of in silico synaptic connections. Journal of Physiology, 590(4):737-752. 
Ecker et al.

Reimann, M. W., King, J. G., Muller, E. B., Ramaswamy, S., and Markram, H. (2015). An algorithm to predict the connectome of neural microcircuits. Frontiers in computational neuroscience, 9(120).

Rozov, A., Burnashev, N., Sakmann, B., and Neher, E. (2001). Transmitter release modulation by intracellular $\mathrm{Ca} 2+$ buffers in facilitating and depressing nerve terminals of pyramidal cells in layer $2 / 3$ of the rat neocortex indicates a target cell-specific difference in presynaptic calcium dynamics. Journal of Physiology, 531(3):807-826.

Sik, A., Penttonen, M., Ylinen, A., and Buzsáki, G. (1995). Hippocampal CA1 Interneurons: An in vivo Intracellular Labeling Study. Journal of Neuroscience, 10(15):6651-6665.

Spruston, N., Jaffe, D. B., Williams, S. H., and Johnston, D. (1993). Voltage- and space-clamp errors associated with the measurement of electrotonically remote synaptic events. Journal of Neurophysiology, $70(2): 781-802$.

Spruston, N., Jonas, P., and Sakmann, B. (1995). Dendritic glutamate receptor channels in rat hippocampal CA3 and CAl pyramidal neurons. Journal of Physiology, 482(2):325-352.

Stuart, G., Schiller, J., and Sakmann, B. (1997). Action potential initiation and propagation in rat neocortical pyramidal neurons. Journal of Physiology, 505(3):617-632.

Takács, V. T., Klausberger, T., Somogyi, P., Freund, T. F., and Gulyás, A. I. (2012). Extrinsic and local glutamatergic inputs of the rat hippocampal CA1 area differentially innervate pyramidal cells and interneurons. Hippocampus, 22(6):1379-1391.

Tsodyks, M. and Markram, H. (1997). The neural code between neocortical pyramidal neurons depends on neurotransmitter release probability. PNAS, 94:719-723.

Van Geit, W., Gevaert, M., Chindemi, G., Rössert, C., Courcol, J.-D., Muller, E., Schürmann, F., Segev, I., and Markram, H. (2016). BluePyOpt: Leveraging open source software and cloud infrastructure to optimise model parameters in neuroscience. Frontiers in Neuroinformatics, 10(17).

Vida, I., Halasy, K., Szinyei, C., Somogyi, P., and Buhl, E. H. (1998). Unitary IPSPs evoked by interneurons at the stratum radiatum — stratum lacunosum-moleculare border in the CA1. Journal of Physiology, 506(3):755-773.

Wheeler, D. W., White, C. M., Rees, C. L., Komendantov, A. O., Hamilton, D. J., and Ascoli, G. A. (2015). Hippocampome.org: A knowledge base of neuron types in the rodent hippocampus. eLife, 4(e09960).

Williams, S. R. and Mitchell, S. J. (2008). Direct measurement of somatic voltage clamp errors in central neurons. Nature Neuroscience, 11(7):790-798. 
bioRxiv preprint doi: $\mathrm{https}$ ://doi.org/101101/716480; this version posted July 26, 2019. The copyright holder for this preprint (which was not certified by peer review) is the author/funder. All rights reserved. No reuse allowed without permission.

Ecker et al.

Integration of CA1 synapse physiology in silico

\section{Experimental data}

Paired recordings:

Kinetic parameters (ms)

- PSP amplitudes (mV)

- Holding potentials (mV)
- Calcium concentrations (mM)

- Raw traces

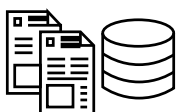

2. Data integration
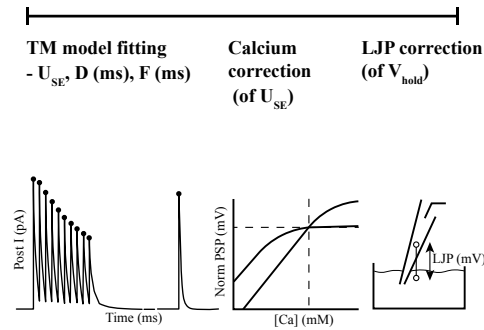

3. In silico experiments

Space clamp correction - peak conductances (nS)

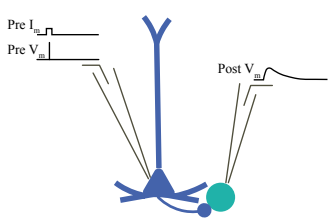

4. Parameter generalization

PSPs of experimentally characterized pathways $\downarrow$

PSPs of uncharacterized pathways

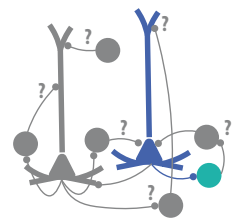

Figure 1 - Ecker et al. 
Ecker et al.

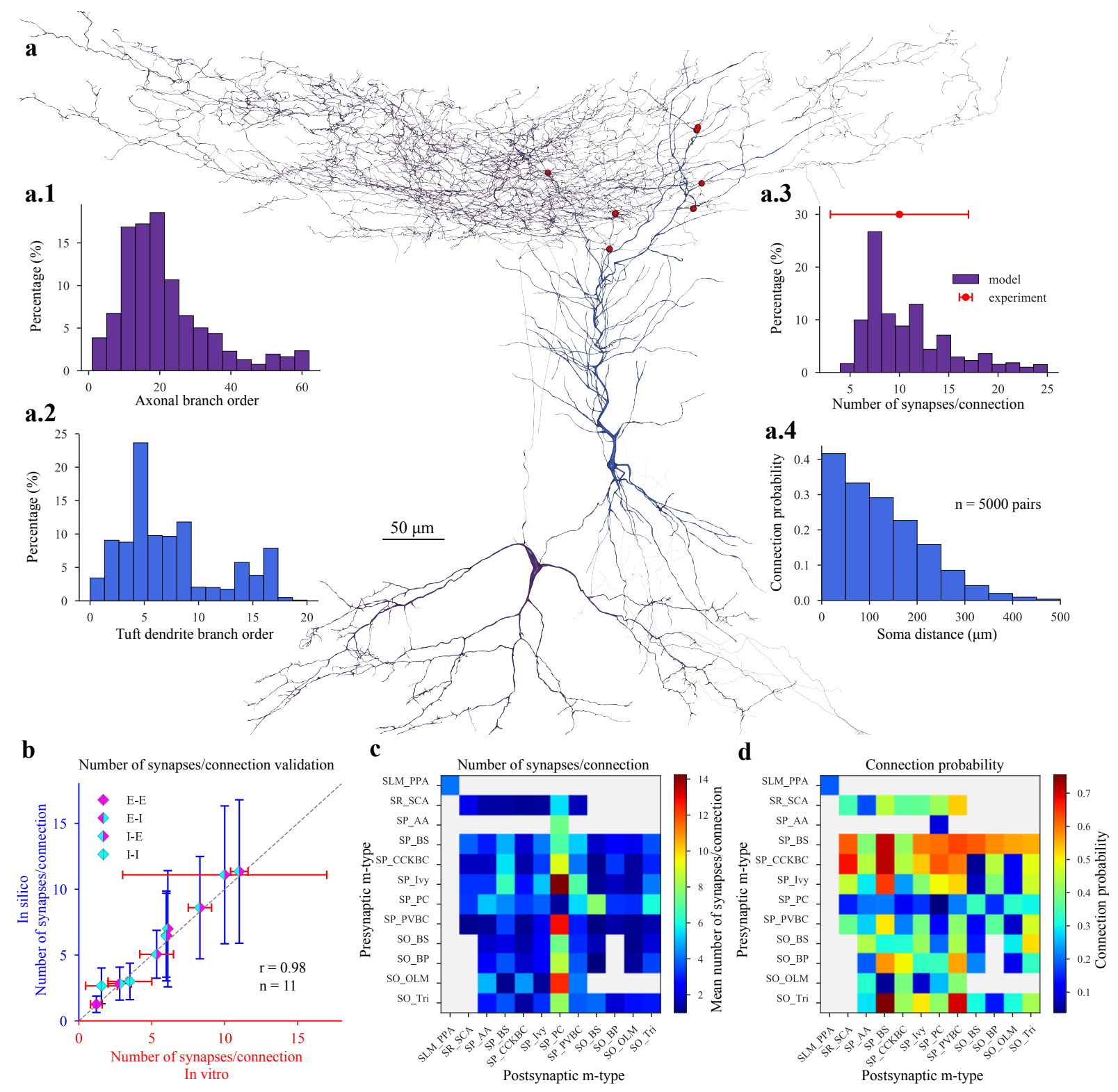

Figure 2 - Ecker et al. 
bioRxiv preprint doi: https://doi.org/10.1101/716480; this version posted July 26, 2019. The copyright holder for this preprint (which was not certified by peer review) is the author/funder. All rights reserved. No reuse allowed without permission.

Ecker et al.

Integration of CA1 synapse physiology in silico

a

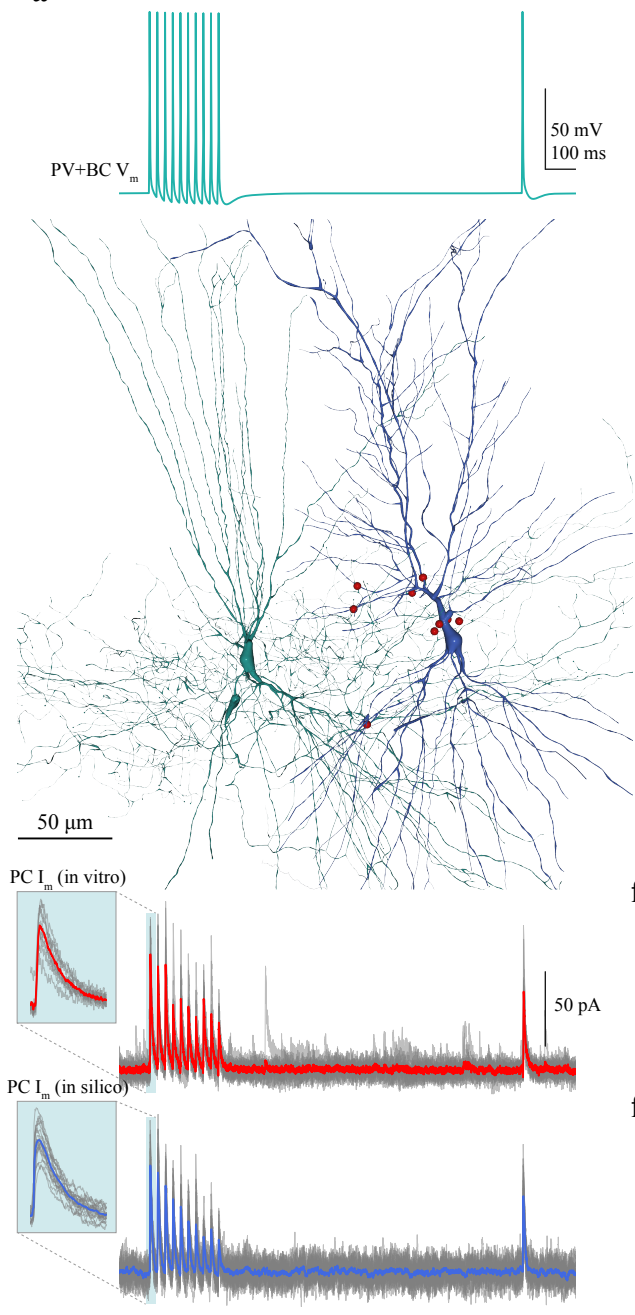

b

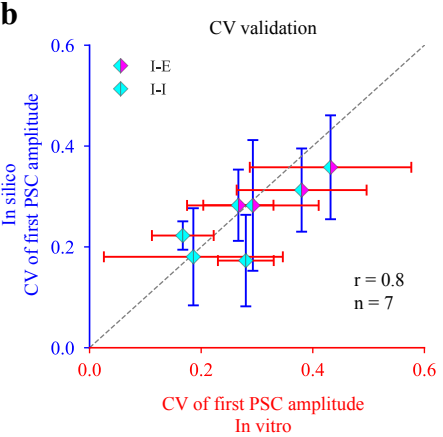

d

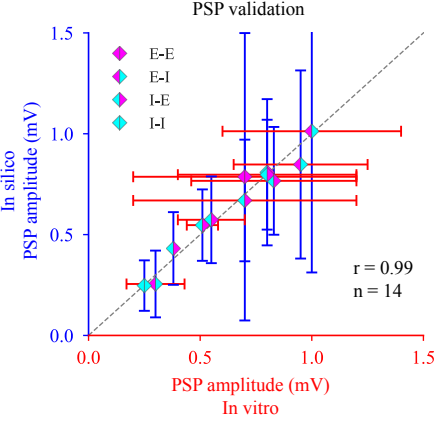

f.1

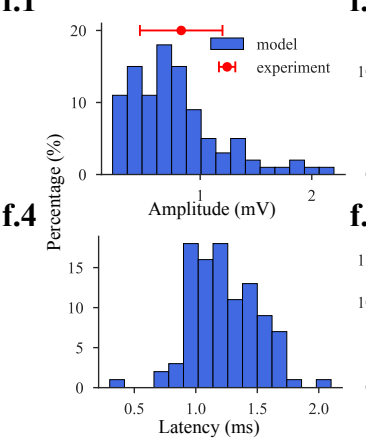

c

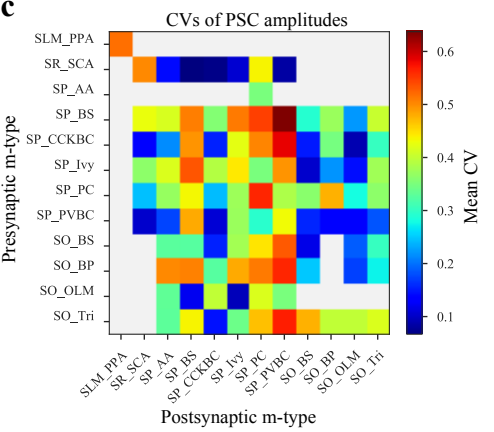

e

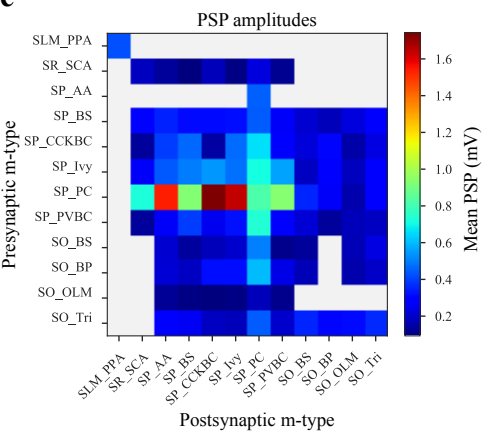

f.3

f.2

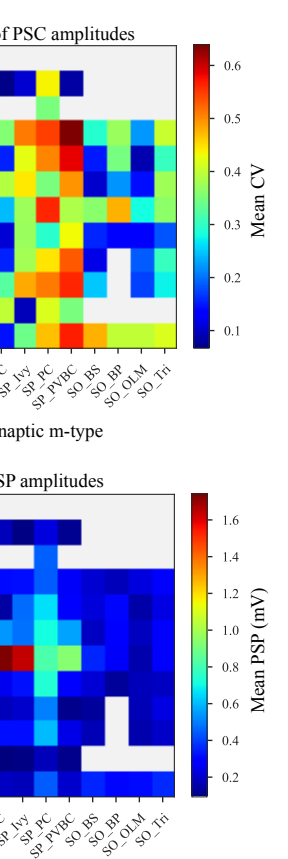

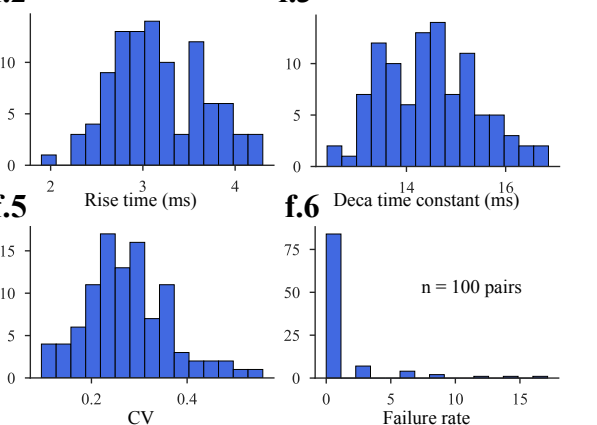

Figure 3 - Ecker et al. 
bioRxiv preprint doi: $\mathrm{https}$ ://doi. org/10.1101/716480; this version posted July 26, 2019. The copyright holder for this preprint (which was not certified by peer review) is the author/funder. All rights reserved. No reuse allowed without permission.

Ecker et al.

Integration of CA1 synapse physiology in silico

a

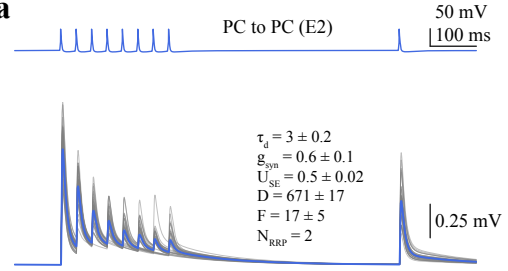

b

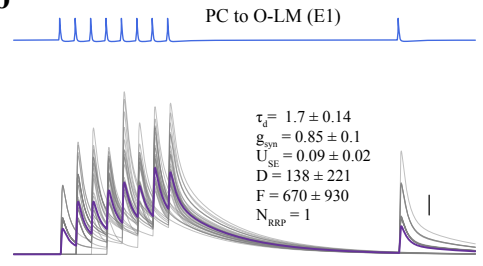

c

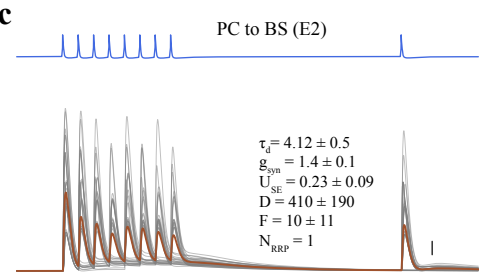

d

UUU $\mathrm{PC}$ to $\mathrm{CCK}+\mathrm{BC}$ (E2)

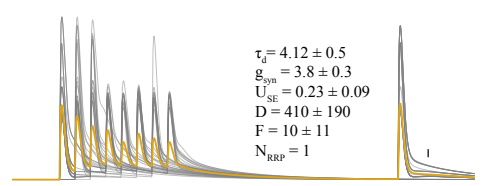

e

HuH O-LM to PC (I2)

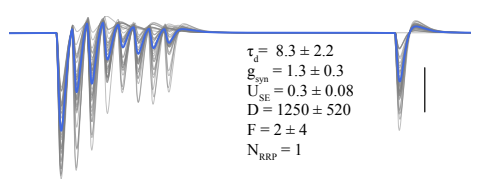

$\mathrm{D} D=1250 \pm 520$
$\mathrm{~F}=2 \pm 4$

$\mathrm{N}_{\text {RRP }}=1$

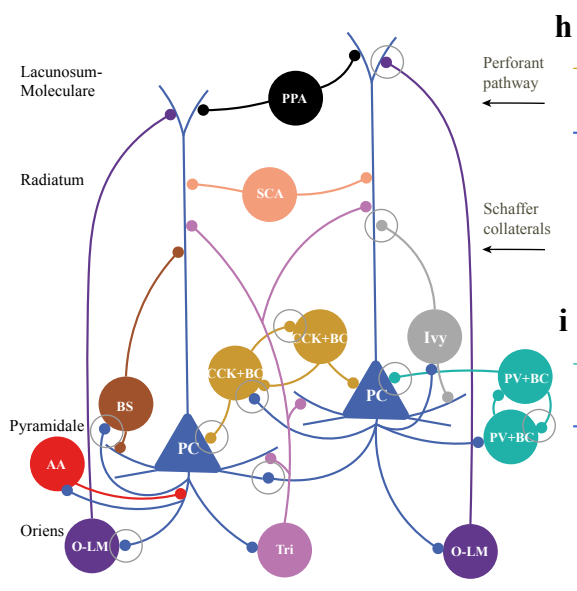

h

g

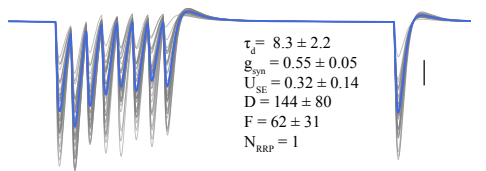

WuHUU CCK+BC to PC(13)

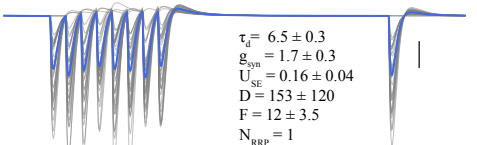

$\mathrm{N}_{\mathrm{RRP}}=1$

f

UUUUU CCK+BC to CCK+BC (II)

j

UUHU PV+BC to PV+BC (I2)

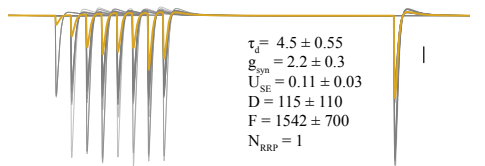

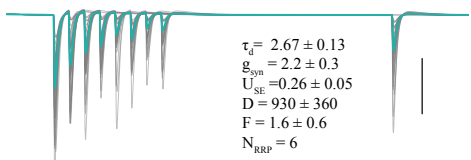

Figure 4 - Ecker et al. 


\title{
Supplementary Material: Data-driven integration of hippocampal CA1 synapse physiology in silico
}

\author{
András Ecker, Armando Romani, Sára Sáray, Szabolcs Káli, Michele Migliore, Audrey \\ Mercer, Henry Markram, Eilif Muller, Srikanth Ramaswamy
}

\section{Supplementary Methods}

The Tsodyks-Markram model of short-term plasticity underwent many changes in the years twenty years. For a recent and consistent review see Hennig (2013). Furthermore, the equations are sometimes shown in the form of differential equations (Tsodyks and Markram, 1997; Tsodyks et al., 2000; Fuhrmann et al., 2002, 2004; Loebel et al., 2009; Hennig, 2013), while in other papers the iterative solution evaluated at spike arrivals is presented (Markram et al., 1998; Maass and Markram, 2002). The version used in this article follows the formalism presented in Hennig (2013):

$$
\begin{gathered}
\frac{d R(t)}{d t}=\frac{1-R(t)}{D}-U(t) R(t) \delta\left(t-t_{\text {spike }}\right) \\
\frac{d U(t)}{d t}=\frac{U_{S E}-U(t)}{F}+U_{S E}(1-U(t)) \delta\left(t-t_{\text {spike }}\right)
\end{gathered}
$$

where $R(t)$ is the fraction of available resources, $U(t)$ is the release probability, $D$, and $F$ are depression and facilitation time constants respectively. $U_{S E}$ is the absolute release probability also known as the release probability in the absence of facilitation. $\delta(t)$ is the Dirac delta function and $t_{\text {spike }}$ indicates the timing of a presynaptic spike. Each action potential in a train elicits an $A_{S E} U\left(t_{\text {spike }}\right) R\left(t_{\text {spike }}\right)$ amplitude PSC, where $A_{S E}$ is the absolute synaptic efficacy and is linked to the $N q$ part of the quantal model, where $N$ is the number of release sites and $q$ is the quantal amplitude. $R=1$, and $U=U_{S E}$ are assumed before the first spike. In our simulations, we implement Fuhrmann et al. (2002) as the stochastic generalization of the model. The equation of the release probability is slightly different in that article and it reads as follows:

$$
\frac{d U(t)}{d t}=-\frac{U(t)}{F}+U_{S E}(1-U(t)) \delta\left(t-t_{\text {spike }}\right)
$$

According to this equation $U(t)$ decays to 0 (the wording of the articles suggest a decay to "the baseline"). To recover the definition of $U_{S E}$ as the release probability in absence of spikes (or U as the constant release probability in the first Tsodyks and Markram (1997) paper concentrating only on depressing connections) the $+U_{S E}(1-U(t))$ has to be evaluated before the release happens. On the other hand, the $-U(t) R(t)$ jump in the equation of $\mathrm{R}$ still has to be evaluated after the event in order to be consistent with $R$ being 1 in the absence of spikes. In this view $U(t)$ is mostly zero and at spike arrivals, before release happens it jumps to $U_{S E}$. From the biophysical point of view, this can be seen as a calcium-based model, where a quick calcium influx leads to release. On the other hand, in the Hennig (2013) version $U(t)$ decays to its baseline $U_{S E}$ value and the $U_{S E}(1-U(t))$ jump happens after the release. When fitting the deterministic TM model to experimental data as well as simulating the stochastic version we use an event-based solution, meaning that the equations are only evaluated at spike times (as opposed to the ODE form). 
Ecker et al.

For the Fuhrmann et al. (2002) version the iterative update is:

$$
\begin{aligned}
& R_{n+1}=1+\left(R_{n}-1\right) \exp \left(-\frac{\Delta t}{D}\right) \\
& U_{n+1}=U_{n} \exp \left(-\frac{\Delta t}{F}\right) \\
& U_{n+1}=U_{n+1}+U_{S E}\left(1-U_{n+1}\right) \\
& A_{n+1}=A_{S E} U_{n+1} R_{n+1} \\
& R_{n+1}=R_{n+1}-U_{n+1} R_{n+1}
\end{aligned}
$$

where $\Delta t$ is the the time between the $(n+1)$ th and $n$th spike and $A_{n}$ is the $n$th amplitude. On the other hand, the Hennig (2013) version (used to fit models in Kohus et al. (2016)) is:

$$
\begin{aligned}
& R_{n+1}=1+\left(R_{n}-1\right) \exp \left(-\frac{\Delta t}{D}\right) \\
& U_{n+1}=U_{S E}+\left(U_{n}-U_{S E}\right) \exp \left(-\frac{\Delta t}{F}\right) \\
& A_{n+1}=A_{S E} U_{n+1} R_{n+1} \\
& R_{n+1}=R_{n+1}-U_{n+1} R_{n+1} \\
& U_{n+1}=U_{n+1}+U_{S E}\left(1-U_{n+1}\right)
\end{aligned}
$$

None of these forms are presented in the literature. Both Markram et al. (1998) and Maass and Markram (2002) put the jump terms into the decaying exponential part as follows:

$$
\begin{aligned}
R_{n+1} & =1+\left(R_{n}-1-U_{n} R_{n}\right) \exp \left(-\frac{\Delta t}{D}\right) \\
U_{n+1} & =U_{S E}+\left(U_{n}-U_{S E}+U_{S E}\left(1-U_{n}\right)\right) \exp \left(-\frac{\Delta t}{F}\right) \\
& =U_{S E}+U_{n}\left(1-U_{S E}\right) \exp \left(-\frac{\Delta t}{F}\right) \\
& =U_{n} \exp \left(-\frac{\Delta t}{F}\right)+U_{S E}\left(1-U_{n} \exp \left(-\frac{\Delta t}{F}\right)\right) \\
A_{n+1} & =A_{S E} U_{n+1} R_{n+1}
\end{aligned}
$$

Using the initialization $R_{1}=1, U_{1}=U_{S E}$ and calculating the first two amplitudes with all 3 versions (Fuhrmann et al. (2002), Hennig (2013) and Maass and Markram (2002)) one gets:

$$
\begin{gathered}
A_{1}=A_{S E} U_{S E} \\
A_{2}=A_{S E}\left[U_{S E}+\left(U_{S E}-U_{S E}^{2}\right) \exp \left(-\frac{\Delta t}{F}\right)\right]\left(1-U_{S E} \exp \left(-\frac{\Delta t}{D}\right)\right)
\end{gathered}
$$

With simulations, it is also possible to show that all the other amplitudes in response to a spike train will be the same for all versions. Thus, the 3 event-based models presented above are equivalent even if it would be hard to confirm by algebra. We present the Hennig (2013) formalism in the article since we find it more intuitive that both Dirac deltas are evaluated at the same point (after the PSC amplitude is calculated) and is more in line with the wording of the papers, but emphasize that it is consistent with the other versions and the fits presented in Markram et al. (2015). 
Ecker et al.

Supplementary Material

\section{Supplementary Figures}

a

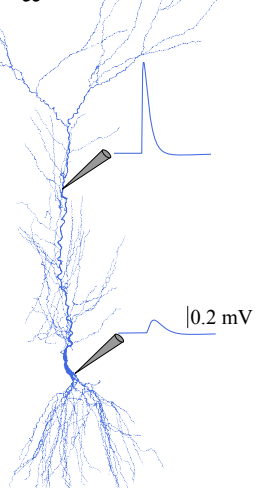

b

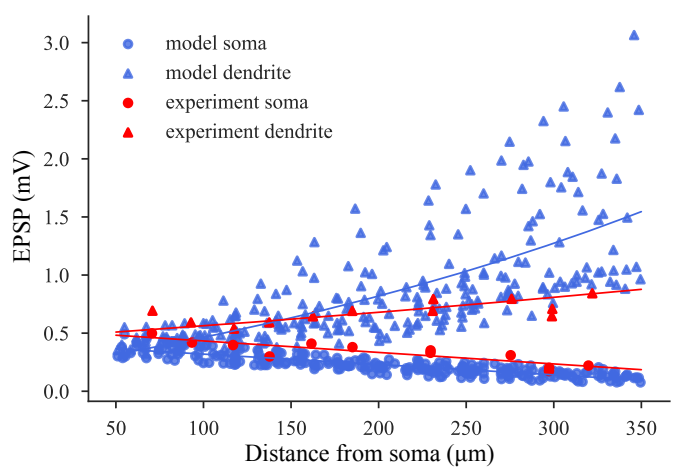

Figure S1: PSP attenuation. Validation of PSP attenuation against experimental data from Magee and Cook (2000). a: EPSC like currents were injected to the apical dendrites of the different pyramidal cell models from Migliore et al. (2018) and PSPs were measured at the injection site and at the soma. b: Summary of all models injected at different sites (in blue) and comparison to experimental data (in red). 
Ecker et al.

Supplementary Material

$\mathbf{a}$

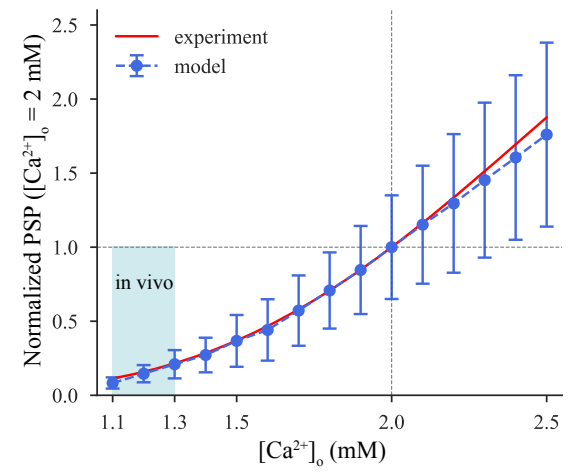

b

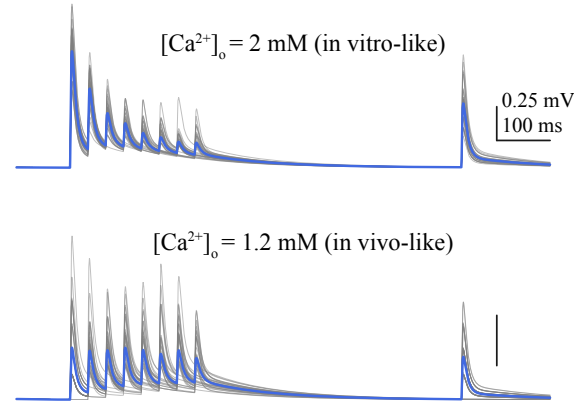

Figure S2: Calcium sensitivity of synaptic physiology. a: PC to PC PSP amplitudes at different extracellular calcium concentrations (normalized to $2 \mathrm{mM}$ ). Red curve indicates the experimentally measured scaling function which was applied to scale the $U_{S E}$ parameter of the TM model. Shaded light blue area indicates the in vivo range 1.1-1.3 mM. b: Same in silico PC to PC pair at two different extracellular calcium concentrations. In vitro like is shown on top, while the in vivo one at the bottom. Single trials $(\mathrm{n}=35)$ are shown in gray and their average in blue. Postsynaptic cells were held at $-65 \mathrm{mV}$ in in silico current-clamp mode. 
Supplementary Tables

Table S1: Summary of paired recording experiments from CA1 in voltage-clamp mode (PSCs in pA). Holding potentials are not corrected for the indicated liquid junction potential. * in the rise time constant column indicates $20-80 \%$ rise time, instead of $10-90 \%$. Abbreviations are as in Figure $\mathbf{2} \mathbf{b}$

\begin{tabular}{|c|c|c|c|c|c|c|c|c|c|c|c|}
\hline Presyn. & Postsyn. & Animal & Elect. & $\begin{array}{c}\text { Ampl. } \\
(\mathbf{p A})\end{array}$ & $\begin{array}{l}\text { Rise } \\
(\mathrm{ms})\end{array}$ & $\begin{array}{c}\text { Decay } \\
(\mathrm{ms})\end{array}$ & $\begin{array}{l}\text { Hold. } \\
(\mathrm{mV})\end{array}$ & $\begin{array}{l}{\left[C a^{2+}\right]} \\
(\mathbf{m M})\end{array}$ & $\begin{array}{l}\text { Temp. } \\
{\left[{ }^{\circ} \mathbf{C}\right]}\end{array}$ & $\begin{array}{c}\text { LJP } \\
(\mathbf{m V})\end{array}$ & Reference \\
\hline $\mathrm{AA}$ & $\mathrm{PC}$ & rat (P10-17) & patch & $308 \pm 103$ & $0.8 \pm 0.1$ & $11.2 \pm 0.9$ & -70 & 3 & $\sim 30$ & - & Maccaferri et al. (2000) \\
\hline $\mathrm{BS}$ & $\mathrm{PC}$ & rat (P10-17) & patch & Fig6) A,B & $2 \pm 0.2$ & $16.1 \pm 1.1$ & -70 & 3 & $\sim 30$ & - & Maccaferri et al. (2000) \\
\hline CCKBC & $\mathrm{PC}$ & rat (P16-20) & patch & $118 \pm 13$ & $0.73 \pm 0.05$ & $6.8 \pm 0.2$ & -70 & 2 & 33 & - & Neu et al. (2007) \\
\hline CCKBC & $\mathrm{PC}$ & rat (P16-21) & patch & $53.7 \pm 17.2$ & - & - & -70 & 2 & 33 & - & Földy et al. (2007) \\
\hline CCKBC & $\mathrm{PC}$ & rat (P17-22) & patch & $115.4 \pm 10.8$ & $0.63 \pm 0.04$ & $6.47 \pm 0.27$ & $-58.3 \pm 0.5$ & 2 & 33 & - & Lee et al. (2010) \\
\hline NGF & $\mathrm{PC}$ & rat (P18-24) & patch & $4.9 \pm 1$ & - & $50 \pm 4.9$ & $-50 \pm 2$ & 2.5 & $33 \pm 2$ & 12 & Price et al. (2008) \\
\hline OLM & $\mathrm{PC}$ & rat $(\mathrm{P} 10-17)$ & patch & $26 \pm 10$ & $6.2 \pm 0.6$ & $20.8 \pm 1.7$ & -70 & 3 & $\sim 30$ & - & Maccaferri et al. (2000) \\
\hline $\mathrm{PVBC}$ & $\mathrm{PC}$ & rat (P16-21) & patch & $43.6 \pm 17.9$ & - & - & -70 & 2 & 33 & - & Földy et al. (2007) \\
\hline SCA & $\mathrm{PC}$ & rat $(\mathrm{P} 17-22)$ & patch & $60.2 \pm 8.1$ & $1.43 \pm 0.12$ & $8.3 \pm 0.44$ & $-58.1 \pm 0.8$ & 2 & 33 & - & Lee et al. (2010) \\
\hline NGF & NGF & rat (P12-21) & patch & $20.97 \pm 23.68$ & & $42.05 \pm 22.03$ & -50 & 2.5 & $33-35$ & - & Price et al. (2005) \\
\hline NGF & NGF & rat (P18-22) & patch & $85.3 \pm 9.6$ & $3.69 \pm 0.34^{*}$ & $60.3 \pm 4.7$ & -65 & 2 & $33 \pm 1$ & - & Karayannis et al. (2010) \\
\hline OLM & NGF & rat (P18-20) & patch & 19.2 & 2.2 & 10.8 & -50 & 2 & $33 \pm 1$ & - & Elfant et al. (2008) \\
\hline OLM & PVBC & rat $(\mathrm{P} 18-20)$ & patch & $11.7 \pm 1$ & $2.6 \pm 1.3$ & $16.5 \pm 3.9$ & -50 & 2 & $33 \pm 1$ & - & Elfant et al. (2008) \\
\hline OLM & $\mathrm{SCA}$ & rat (P18-20) & patch & $19.5 \pm 4.7$ & $1.9 \pm 0.4$ & $31.2 \pm 4.5$ & -50 & 2 & $33 \pm 1$ & - & Elfant et al. (2008) \\
\hline
\end{tabular}


Table S2: Summary of paired recording experiments from CA1 in current-clamp mode (PSPs in mV). No LJP correction is necessary since all recordings were obtained with sharp electrodes. ${ }^{*}$ in the half width column indicates decay time constant instead of half width. Abbreviations are as in Figure $\mathbf{2} \mathbf{b}$

\begin{tabular}{|c|c|c|c|c|c|c|c|c|c|c|c|}
\hline Presyn. & Postsyn. & Animal & Elect. & $\begin{array}{c}\text { Ampl. } \\
(\mathrm{mV})\end{array}$ & $\begin{array}{l}\text { Rise } \\
(\mathrm{ms})\end{array}$ & $\begin{array}{c}\text { HalfW } \\
(\mathrm{ms})\end{array}$ & $\begin{array}{l}\text { Hold. } \\
(\mathrm{mV})\end{array}$ & $\begin{array}{l}{\left[\mathrm{Ca}^{2+}\right]} \\
(\mathbf{m M})\end{array}$ & $\begin{array}{c}\text { Temp. } \\
{\left[{ }^{\circ} \mathbf{C}\right]}\end{array}$ & $\begin{array}{c}\text { LJP } \\
(\mathrm{mV})\end{array}$ & Reference \\
\hline $\mathrm{PC}$ & $\mathrm{PC}$ & rat $(100-180 \mathrm{~g})$ & sharp & $0.7 \pm 0.5$ & $2.7 \pm 0.19$ & $16.8 \pm 4.1$ & $-67-70$ & 2.5 & $34-36$ & $\varnothing$ & Deuchars and Thomson (1996) \\
\hline AA & $\mathrm{PC}$ & $\operatorname{rat}(90-160 \mathrm{~g})$ & sharp & $0.51 \pm 0.07$ & $5 \pm 0.2$ & $45.6 \pm 2$ & $-53 \pm 1$ & 2.5 & $34-36$ & $\varnothing$ & Pawelzik et al. (1999) \\
\hline $\mathrm{BS}$ & $\mathrm{PC}$ & rat $(90-160 \mathrm{~g})$ & sharp & $0.86 \pm 0.55$ & $8.5 \pm 3.6$ & $43.9 \pm 13.9$ & $-57.6 \pm 4.4$ & 2.5 & $34-36$ & $\varnothing$ & Pawelzik et al. (1999) \\
\hline $\mathrm{BS}$ & $\mathrm{PC}$ & rat $(120-200 \mathrm{~g})$ & sharp & $0.55 \pm 0.15$ & $7.4 \pm 1.4$ & $54.6 \pm 4.2$ & $-58.5 \pm 0.5$ & 2. & $34-36$ & $\varnothing$ & Pawelzik et al. (2002) \\
\hline $\mathrm{BS}$ & $\mathrm{PC}$ & rat $(140-200 \mathrm{~g})$ & sharp & $0.8 \pm 0.6$ & $8.4 \pm 3.2$ & $42.1 \pm 17$ & -53 & 2.5 & $33 \pm 1$ & $\varnothing$ & Fuentealba et al. (2008) \\
\hline CCKBC & $\mathrm{PC}$ & rat $(120-200 \mathrm{~g})$ & sharp & $1.17 \pm 0.44$ & $5.4 \pm 2.5$ & $35.5 \pm 19.5$ & $-65-85$ & 2.5 & $34-36$ & $\varnothing$ & Ali et al. (1999) \\
\hline CCKBC & $\mathrm{PC}$ & rat $(100-200 \mathrm{~g})$ & sharp & $1.47 \pm 1.06$ & $6 \pm 2.2$ & $47.6 \pm 13.3$ & $-55-60$ & $2.5 ?$ & $34-36$ & $\varnothing$ & Thomson et al. (2000) \\
\hline CCKBC & $\mathrm{PC}$ & rat $(120-200 \mathrm{~g})$ & sharp & $0.7 \pm 0.5$ & $6.5 \pm 1.5$ & $44.2 \pm 10.1$ & $-58.6 \pm 3.3$ & 2.5 & $34-36$ & $\varnothing$ & Pawelzik et al. (2002) \\
\hline Ivy & $\mathrm{PC}$ & rat $(140-200 \mathrm{~g})$ & sharp & $0.8 \pm 0.4$ & $2.8 \pm 0.2$ & $54.1 \pm 13.8$ & -57 & 2.5 & $33 \pm 1$ & $\varnothing$ & Fuentealba et al. (2008) \\
\hline $\mathrm{PV}+\mathrm{BC}$ & $\mathrm{PC}$ & rat $(150 \mathrm{~g}<)$ & sharp & $0.45 \pm 0.24$ & $4.6 \pm 3.2$ & $32.4 \pm 18^{*}$ & $-57.8 \pm 4.6$ & 2 & $34-35$ & $\varnothing$ & Buhl et al. (1995) \\
\hline $\mathrm{PV}+\mathrm{BC}$ & $\mathrm{PC}$ & rat $(120-200 \mathrm{~g})$ & sharp & $1.17 \pm 0.57$ & $4.5 \pm 2$ & $30.4 \pm 11.6$ & $-65-85$ & 2.5 & $34-36$ & $\varnothing$ & Ali et al. (1999) \\
\hline $\mathrm{PV}+\mathrm{BC}$ & $\mathrm{PC}$ & rat $(90-160 \mathrm{~g})$ & sharp & $0.81 \pm 0.92$ & $6.8 \pm 2.7$ & $47.2 \pm 16.9$ & $-54.7 \pm 3.8$ & 2.5 & $34-36$ & $\varnothing$ & Pawelzik et al. (1999) \\
\hline PVBC & $\mathrm{PC}$ & rat $(100-200 \mathrm{~g})$ & sharp & $1.12 \pm 0.74$ & $5.1 \pm 1.8$ & $39.5 \pm 15.2$ & $-55-60$ & $2.5 ?$ & $34-36$ & $\varnothing$ & Thomson et al. (2000) \\
\hline PVBC & $\mathrm{PC}$ & rat $(120-200 \mathrm{~g})$ & sharp & $0.83 \pm 0.37$ & $5.13 \pm 2.06$ & $38.32 \pm 12$ & $-58.4 \pm 3$ & 2.5 & $34-36$ & $\varnothing$ & Pawelzik et al. (2002) \\
\hline $\mathrm{SCA}$ & $\mathrm{PC}$ & rat $(120-200 \mathrm{~g})$ & sharp & 0.38 & $10 \pm 2.8$ & $45 \pm 2.2$ & $-58.5 \pm 0.5$ & 2.5 & $34-36$ & $\varnothing$ & Pawelzik et al. (2002) \\
\hline Tri & $\mathrm{PC}$ & rat $(120-200 \mathrm{~g})$ & sharp & 0.8 & 5.6 & 48.8 & $-58.5 \pm 0.5$ & 2.5 & $34-36$ & $\varnothing$ & Pawelzik et al. (2002) \\
\hline $\mathrm{PC}$ & $\mathrm{BS}$ & rat $(90-180 \mathrm{~g})$ & sharp & $3.4 \pm 3.1$ & $1.2 \pm 0.5$ & $7.6 \pm 2.6$ & -66 & 2.5 & 34-35 & $\varnothing$ & Ali et al. (1998) \\
\hline $\mathrm{PC}$ & $\mathrm{BS}$ & rat $(120-200 \mathrm{~g})$ & sharp & $0.95 \pm 0.3$ & $1.2 \pm 0.2$ & $10.4 \pm 1.6$ & $-66 \pm 1$ & 2.5 & $34-36$ & $\varnothing$ & Pawelzik et al. (2002) \\
\hline $\mathrm{PC}$ & $\mathrm{BS}$ & rat $(140-200 \mathrm{~g})$ & sharp & $1.8 \pm 2.3$ & $1.5 \pm 0.3$ & $6.4 \pm 2.7$ & -60 & 2.5 & $33 \pm 1$ & $\varnothing$ & Fuentealba et al. (2008) \\
\hline $\mathrm{PC}$ & CCKBC & rat $(120-200 \mathrm{~g})$ & sharp & $2 \pm 2.1$ & $1 \pm 0.4$ & $6.1 \pm 1.5$ & $-67 \pm 3$ & 2.5 & $34-36$ & $\varnothing$ & Pawelzik et al. (2002) \\
\hline $\mathrm{PC}$ & Ivy & rat $(140-200 \mathrm{~g})$ & sharp & $2.9 \pm 2.2$ & $1.5 \pm 0.3$ & $11.5 \pm 1.5$ & -60 & 2.5 & $33 \pm 1$ & $\varnothing$ & Fuentealba et al. (2008) \\
\hline $\mathrm{PC}$ & OLM & rat $(90-150 \mathrm{~g})$ & sharp & $0.93 \pm 1.06$ & $1.2 \pm 0.5$ & $7.5 \pm 0.7$ & $-70 \pm 2.3$ & 2.5 & $34-36$ & $\varnothing$ & Ali and Thomson (1998) \\
\hline $\mathrm{PC}$ & PVBC & rat $(90-180 \mathrm{~g})$ & sharp & $1.4 \pm 1.05$ & $0.88 \pm 0.44$ & $5.4 \pm 2.2$ & -66 & 2.5 & $34-35$ & $\varnothing$ & Ali et al. (1998) \\
\hline $\mathrm{PC}$ & PVBC & rat $(120-200)$ & sharp & $3.51 \pm 2.9$ & $1 \pm 0.3$ & $5.74 \pm 1.78$ & -67 & 2.5 & $34-36$ & $\varnothing$ & Pawelzik et al. (2002) \\
\hline $\mathrm{BC}$ & $\mathrm{BS}$ & rat $(150 \mathrm{~g})$ & sharp & 0.37 & 1 & 5.6 & -55 & 2 & $34-35$ & $\varnothing$ & Cobb et al. (1997) \\
\hline $\mathrm{BC}$ & $\mathrm{BS}$ & rat $(120-180 \mathrm{~g})$ & sharp & $1 \pm 0.4$ & $1.65 \pm 0.5$ & $15.6 \pm 2.8$ & $-63 \pm 4.4$ & 2.5 & $34-36$ & $\varnothing$ & Pawelzik et al. (2003) \\
\hline $\mathrm{BC}$ & $\mathrm{BC}$ & rat $(150 \mathrm{~g})$ & sharp & 0.25 & 1.3 & 27 & -59 & 2 & $34-35$ & $\varnothing$ & Cobb et al. (1997) \\
\hline $\mathrm{BC}$ & $\mathrm{BC}$ & rat $(120-180 \mathrm{~g})$ & sharp & $1.1 \pm 0.47$ & $2.5 \pm 0.9$ & $18.7 \pm 9.1$ & $-59 \pm 4$ & 2.5 & $34-36$ & $\varnothing$ & Pawelzik et al. (2003) \\
\hline$\overline{B S}$ & $\mathrm{BC}$ & rat $(120-180 \mathrm{~g})$ & sharp & $0.7 \pm 0.4$ & $2.5 \pm 0.8$ & $19.1 \pm 9.5$ & $-59.7 \pm 2.7$ & 2.5 & $34-36$ & $\varnothing$ & Pawelzik et al. (2003) \\
\hline $\mathrm{SCA}$ & SCA & rat $(120-200 \mathrm{~g})$ & sharp & 0.5 & 5 & 34.3 & -58 & 2.5 & $34-36$ & $\varnothing$ & Pawelzik et al. (2002) \\
\hline $\mathrm{SCA}$ & SCA & rat (P18-23) & patch & $0.6 \pm 0.41$ & $7.0 \pm 1.38$ & $41.1 \pm 12.5$ & -55 & 2 & $20-22$ & - & Ali (2007) \\
\hline
\end{tabular}


Ecker et al.

Supplementary Material

Table S3: Validation of number of synapses per connections. See Figure 2 b). Abbreviations are as in Figure $2 \mathrm{~b}$

\begin{tabular}{llccl}
\hline Presyn. & Postsyn. & Reference data & Model & Reference \\
\hline PC & PC & $1.2 \pm 0.4$ & $1.26 \pm 0.6$ & Deuchars and Thomson (1996) \\
\hline AA & PC & 6.1 & $7 \pm 4.4$ & Buhl et al. (1994b) \\
\hline BS & PC & 6 & $6.5 \pm 3.2$ & Buhl et al. (1994a) \\
\hline CCKBC & PC & $8.3 \pm 0.8$ & $8.6 \pm 3.9$ & Földy et al. (2010) \\
\hline OLM & PC & $10 \pm 7$ & $11 \pm 5.2$ & Maccaferri et al. (2000) \\
\hline PVBC & PC & $11 \pm 0.6$ & $11.3 \pm 5.4$ & Földy et al. (2010) \\
\hline SCA & PC & $5.3 \pm 1.2$ & $5 \pm 1.8$ & Vida et al. (1998) \\
\hline PC & OLM & $2.8 \pm 0.8$ & $2.8 \pm 1.2$ & Biro et al. (2005) \\
\hline PVBC & PV + & $1.54 \pm 1.08$ & $2.6 \pm 1.3$ & Sik et al. (1995) \\
\hline SCA & SCA & $3.5 \pm 1.5$ & $3 \pm 1.4$ & Ali (2011) \\
\hline
\end{tabular}


Ecker et al.

Supplementary Material

Table S4: Validation of the CV of first PSC amplitudes. See Figure $3 \mathbf{b}$ ). Abbreviations are as in Figure 2 b

\begin{tabular}{llccl}
\hline Presyn. & Postsyn. & Reference data & Model & Reference \\
\hline AA & PC & $0.29 \pm 0.11$ & $0.28 \pm 0.13$ & Kohus et al. (2016) \\
\hline CCKBC & PC & $0.43 \pm 0.14$ & $0.36 \pm 0.1$ & Kohus et al. (2016) \\
\hline PVBC & PC & $0.26 \pm 0.06$ & $0.28 \pm 0.07$ & Kohus et al. (2016) \\
\hline SCA & PC & $0.38 \pm 0.11$ & $0.31 \pm 0.08$ & Kohus et al. (2016) \\
\hline CCKBC & CCKBC & $0.18 \pm 0.16$ & $0.18 \pm 0.1$ & Kohus et al. (2016) \\
\hline PVBC & AA & $0.45 \pm 0.11$ & $0.17 \pm 0.09$ & Kohus et al. (2016) \\
\hline PVBC & PVBC & $0.17 \pm 0.05$ & $0.22 \pm 0.02$ & Kohus et al. (2016) \\
\hline
\end{tabular}


Ecker et al.

Supplementary Material

Table S5: Validation of PSP amplitudes. See Figure $3 \mathbf{d}$ ). PC to CCKBC and PC to Ivy are not shown on the figure for visualization purpose. In some cases (indicated with *) outliers were removed from the reference data (see published reference data in Table S1). Abbreviations are as in Figure $\mathbf{2}$ b

\begin{tabular}{llccl}
\hline Presyn. & Postsyn. & Reference data $(\mathbf{m V})$ & Model $(\mathbf{m V})$ & Reference \\
\hline PC & PC & $0.7 \pm 0.5$ & $0.78 \pm 0.71$ & Deuchars and Thomson (1996) \\
\hline AA & PC & $0.51 \pm 0.07$ & $0.55 \pm 0.17$ & Pawelzik et al. (1999) \\
\hline BS & PC & $0.55 \pm 0.15$ & $0.57 \pm 0.21$ & Pawelzik et al. (2002) \\
\hline CCKBC & PC & $0.7 \pm 0.5$ & $0.67 \pm 0.3$ & Pawelzik et al. (2002) \\
\hline Ivy & PC & $0.8 \pm 0.4$ & $0.8 \pm 0.27$ & Fuentealba et al. (2008) \\
\hline PVBC & PC & $0.83 \pm 0.37$ & $0.76 \pm 0.26$ & Pawelzik et al. (2002) \\
\hline SCA & PC & 0.38 & $0.43 \pm 0.18$ & Pawelzik et al. (2002) \\
\hline Tri & PC & 0.8 & $0.8 \pm 0.36$ & Pawelzik et al. (2002) \\
\hline PC & BS & $0.95 \pm 0.3$ & $1 \pm 0.54$ & Pawelzik et al. (2002) \\
\hline PC & CCKBC & $2 \pm 2.1$ & $1.9 \pm 1.35$ & Pawelzik et al. (2002) \\
\hline PC & Ivy & $2.9 \pm 2.2$ & $2.45 \pm 1.5$ & Fuentealba et al. (2008) \\
\hline PC & OLM & $0.3 \pm 0.13^{*}$ & $0.25 \pm 0.16$ & Ali and Thomson (1998) \\
\hline PC & PVBC & $1 \pm 0.4^{*}$ & $1 \pm 0.7$ & Ali et al. (1998) \\
\hline PV)BC & (PV)BC & 0.25 & $0.25 \pm 0.12$ & Cobb et al. (1997) \\
\hline
\end{tabular}




\section{References}

Ali, A. B. (2007). Presynaptic Inhibition of GABAA Receptor-Mediated Unitary IPSPs by Cannabinoid Receptors at Synapses Between CCK-Positive Interneurons in Rat Hippocampus. Journal of Neurophysiology, 98(2):861-869.

Ali, A. B. (2011). CB1 modulation of temporally distinct synaptic facilitation among local circuit interneurons mediated by N-type calcium channels in CA1. Journal of Physiology, 105:1051-1062.

Ali, A. B., Bannister, A. P., and Thomson, A. M. (1999). IPSPs elicited in CA1 pyramidal cells by putative basket cells in slices of adult rat hippocampus. European Journal of Neuroscience, 11(5):1741-1753.

Ali, A. B., Deuchars, J., Pawelzik, H., and Thomson, A. M. (1998). CA1 pyramidal to basket and bistratified cell EPSPs: Dual intracellular recordings in rat hippocampal slices. Journal of Physiology, 507(1):201-217.

Ali, A. B. and Thomson, A. M. (1998). Facilitating pyramid to horizontal oriens-alveus interneurone inputs: Dual intracellular recordings in slices of rat hippocampus. Journal of Physiology, 507(1):185-199.

Biro, A. A., Holderith, N. B., and Nusser, Z. (2005). Quantal Size Is Independent of the Release Probability at Hippocampal Excitatory Synapses. Journal of Neuroscience, 25(1):223-232.

Buhl, E. H., Cobb, S. R., Halasy, K., and Somogyi, P. (1995). Properties of unitary IPSPs evoked by anatomically identified basket cells in the rat hippocampus. European Journal of Neuroscience, 7(9):1989-2004.

Buhl, E. H., Halasy, K., and Somogyi, P. (1994a). Diverse sources of hippocampal unitary inhibitory postsynaptic potentials and the number of synaptic release sites. Nature, 368:823828.

Buhl, E. H., Han, Z.-S., Lörinczi, Z., Stezhka, V. V., Karnup, S. V., and Somogyi, P. (1994b). Physiological Properties of Anatomically Identified AxoAxonic in the Rat Hippocampus. Journal of Neurophysiology, 71(4):1289-1307.

Cobb, S. R., Halasy, K., Vida, I., Nyíri, G., Tamás, G., Buhl, E. H., and Somogyi, P. (1997). Synaptic effects of identified interneurons innervating both interneurons and pyramidal cells in the rat hippocampus. Neuroscience, 79(3):629-648.

Deuchars, J. and Thomson, A. M. (1996). CA1 pyramid-pyramid connections in rat hippocampus in vitro: Dual intracellular recordings with biocytin filling. Neuroscience, 74(4):1009-1018.

Elfant, D., Pal, B. Z., Emptage, N., and Capogna, M. (2008). Specific inhibitory synapses shift the balance from feedforward to feedback inhibition of hippocampal CA1 pyramidal cells. European Journal of Neuroscience, 27(1):104-113.

Földy, C., Lee, S.-h., Morgan, R. J., and Soltesz, I. (2010). Regulation of fast-spiking basket cell synapses by the chloride channel ClC-2. Nature Neuroscience, 13(9):1047-1049.

Földy, C., Lee, S. Y., Szabadics, J., Neu, A., and Soltesz, I. (2007). Cell type - specific gating of perisomatic inhibition by cholecystokinin. Nature neuroscience, 10(9):1128-1130.

Fuentealba, P., Begum, R., Capogna, M., Jinno, S., Márton, L. F., Csicsvari, J., Thomson, A., Somogyi, P., and Klausberger, T. (2008). Ivy Cells: A Population of Nitric-Oxide-Producing, Slow-Spiking GABAergic Neurons and Their Involvement in Hippocampal Network Activity. Neuron, 57(6):917-929. 
Fuhrmann, G., Cowan, A., Segev, I., Tsodyks, M., and Stricker, C. (2004). Multiple mechanisms govern the dynamics of depression at neocortical synapses of young rats. Journal of Physiology, $557(2): 415-438$.

Fuhrmann, G., Segev, I., Markram, H., and Tsodyks, M. (2002). Coding of Temporal Information by Activity-Dependent Synapses. Journal of Neurophysiology, 87(1):140-148.

Hennig, M. H. (2013). Theoretical models of synaptic short term plasticity. Frontiers in Computational Neuroscience, 7(45).

Karayannis, T., Elfant, D., Huerta-Ocampo, I., Teki, S., Scott, R. S., Rusakov, D. A., Jones, M. V., and Capogna, M. (2010). Slow GABA transient and receptor desensitization shape synaptic responses evoked by hippocampal neurogliaform cells. The Journal of neuroscience, 30(29):9898-909.

Kohus, Z., Káli, S., Schlingloff, D., Papp, O., Rovira-Esteban, L., Freund, T. F., Hájos, N., and Gulyás, A. I. (2016). Properties and dynamics of inhibitory synaptic communication within the CA3 microcircuits of pyramidal cells and interneurons expressing parvalbumin or cholecystokinin. The Journal of physiology, 594(13):3745-74.

Lee, S.-H., Földy, C., and Soltesz, I. (2010). Distinct endocannabinoid control of GABA release at perisomatic and dendritic synapses in the hippocampus. The Journal of neuroscience, 30(23):7993-8000.

Loebel, A., Silberberg, G., Helbig, D., Markram, H., Tsodyks, M., and Richardson, M. J. E. (2009). Multiquantal release underlies the distribution of synaptic efficacies in the neocortex. Frontiers in Cellular Neuroscience, 3(27).

Maass, W. and Markram, H. (2002). Synapses as dynamic memory buffers. Neural Networks, 15(2):155-161.

Maccaferri, G., Roberts, J. D. B., Szucs, P., Cottingham, C. A., and Somogyi, P. (2000). Cell surface domain specific postsynaptic currents evoked by identified GABAergic neurones in rat hippocampus in vitro. Journal of Physiology, 524(1):91-116.

Magee, J. C. and Cook, E. P. (2000). Somatic EPSP amplitude is independent of synapse location in hippocampal pyramidal neurons. Nature neuroscience, 3(9):895-903.

Markram, H., Wang, Y., and Tsodyks, M. (1998). Differential signaling via the same axon of neocortical pyramidal neurons. PNAS, 95(9):5323-8.

Markram, M., Muller, E., Ramaswamy, S., and Reimann, M. W. (2015). Reconstruction and Simulation of Neocortical Microcircuitry. Cell, 163:456-492.

Migliore, R., Lupascu, C. A., Bologna, L. L., Romani, A., Courcol, J.-D., Antonel, S., Van Geit, W. A. H., Thomson, A. M., Mercer, A., Lange, S., Falck, J., Rössert, C. A., Shi, Y., Hagens, O., Pezzoli, M., Freund, T. F., Kali, S., Muller, E. B., Schürmann, F., Markram, H., and Migliore, M. (2018). The physiological variability of channel density in hippocampal CA1 pyramidal cells and interneurons explored using a unified data-driven modeling workflow. PLOS Computational Biology, 14(9):e1006423.

Neu, A., Földy, C., and Soltesz, I. (2007). Postsynaptic origin of CB1-dependent tonic inhibition of GABA release at cholecystokinin-positive basket cell to pyramidal cell synapses in the CA1 region of the rat hippocampus. The Journal of physiology, 578(1):233-247. 
Pawelzik, H., Bannister, A. P., Deuchars, J., Ilia, M., and Thomson, A. M. (1999). Modulation of bistratified cell IPSPs and basket cell IPSPs by pentobarbitone sodium, diazepam and $\mathrm{Zn2+}$ : Dual recordings in slices of adult rat hippocampus. European Journal of Neuroscience, 11(10):3552-3564.

Pawelzik, H., Hughes, D. I., and Thomson, A. M. (2002). Physiological and morphological diversity of immunocytochemically defined parvalbumin- and cholecystokinin-positive interneurones in CA1 of the adult rat hippocampus. Journal of Comparative Neurology, 443(4):346-367.

Pawelzik, H., Hughes, D. I., and Thomson, A. M. (2003). Modulation of inhibitory autapses and synapses on rat CA1 interneurones by GABAA receptor ligands. Journal of Physiology, 546(3):701-716.

Price, C. J., Cauli, B., Kovács, E. R., Kukik, Á., Lambolez, B., Shigemeto, R., and Capogna, M. (2005). Neurogliaform Neurons Form a Novel Inhibitory Network in the Hippocampal CA1 Area. Journal of Neuroscience, 25(29):6775-6786.

Price, C. J., Scott, R., Rusakov, D. A., and Capogna, M. (2008). GABAB Receptor Modulation of Feedforward Inhibition through Hippocampal Neurogliaform Cells. The Journal of Neuroscience, 28(27):6974-6982.

Sik, A., Penttonen, M., Ylinen, A., and Buzsáki, G. (1995). Hippocampal CA1 Interneurons: An in vivo Intracellular Labeling Study. Journal of Neuroscience, 10(15):6651-6665.

Thomson, A. M., Bannister, A. P., Hughes, D. I., and Pawelzik, H. (2000). Differential sensitivity to Zolpidem of IPSPs activated by morphologically identified CA1 interneurons in slices of rat hippocampus. European Journal of Neuroscience, 12(2):425-436.

Tsodyks, M. and Markram, H. (1997). The neural code between neocortical pyramidal neurons depends on neurotransmitter release probability. PNAS, 94:719-723.

Tsodyks, M., Uziel, A., and Markram, H. (2000). Synchrony generation in recurrent networks with frequency-dependent synapses. The Journal of neuroscience, 20(RC50).

Vida, I., Halasy, K., Szinyei, C., Somogyi, P., and Buhl, E. H. (1998). Unitary IPSPs evoked by interneurons at the stratum radiatum - stratum lacunosum-moleculare border in the CA1. Journal of Physiology, 506(3):755-773. 